\title{
A new FXR ligand chemotype with agonist/antagonist switch
}

Moritz Helmstädter ${ }^{1 \ddagger}$, Jan Vietor ${ }^{1 \ddagger}$, Jana Sommer ${ }^{1}$, Simone Schierle ${ }^{1}$, Sabine Willems ${ }^{1}$, Astrid Kaiser $^{1}$, Jurema Schmidt ${ }^{1}$, Daniel Merk ${ }^{1 *}$

${ }^{1}$ Institute of Pharmaceutical Chemistry, Goethe University Frankfurt, Max-von-Laue-Str. 9, D-60438 Frankfurt, Germany

- Supporting Information -

\section{Table of Contents}

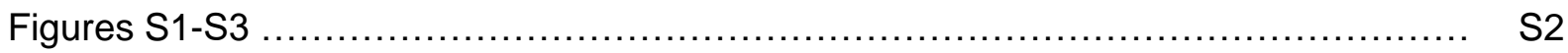

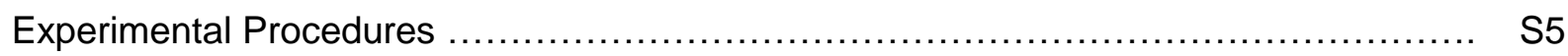

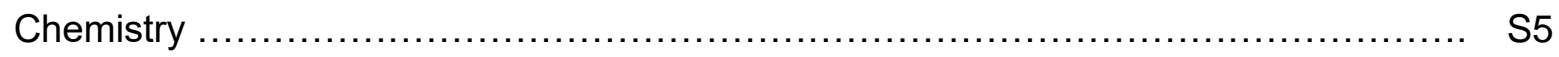

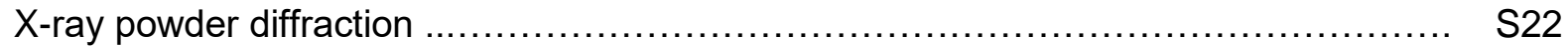

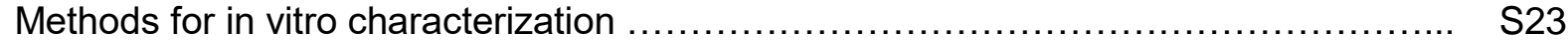

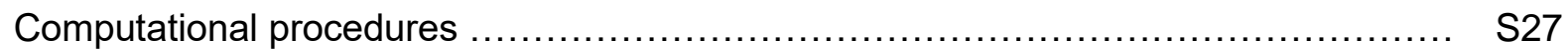

Supporting References $\ldots \ldots \ldots \ldots \ldots \ldots \ldots \ldots \ldots \ldots \ldots \ldots \ldots \ldots \ldots \ldots \ldots \ldots \ldots \ldots \ldots, \quad S 28$ 

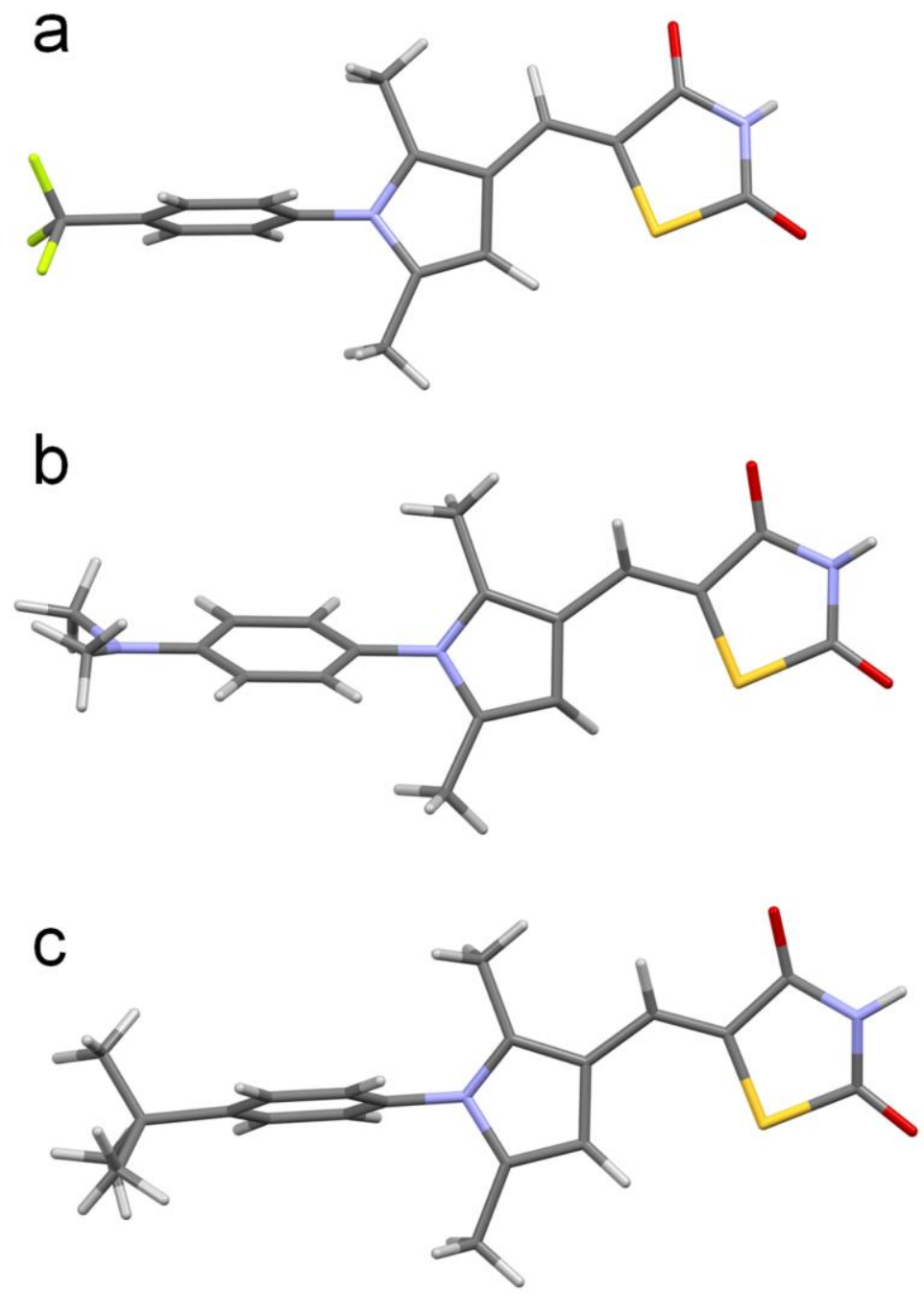

Figure S1. X-ray powder diffraction reveals Z-configuration of thiazolidinediones $\mathbf{1 0}$ (a) $\mathbf{1 3}$ (b) and 17 (c). 


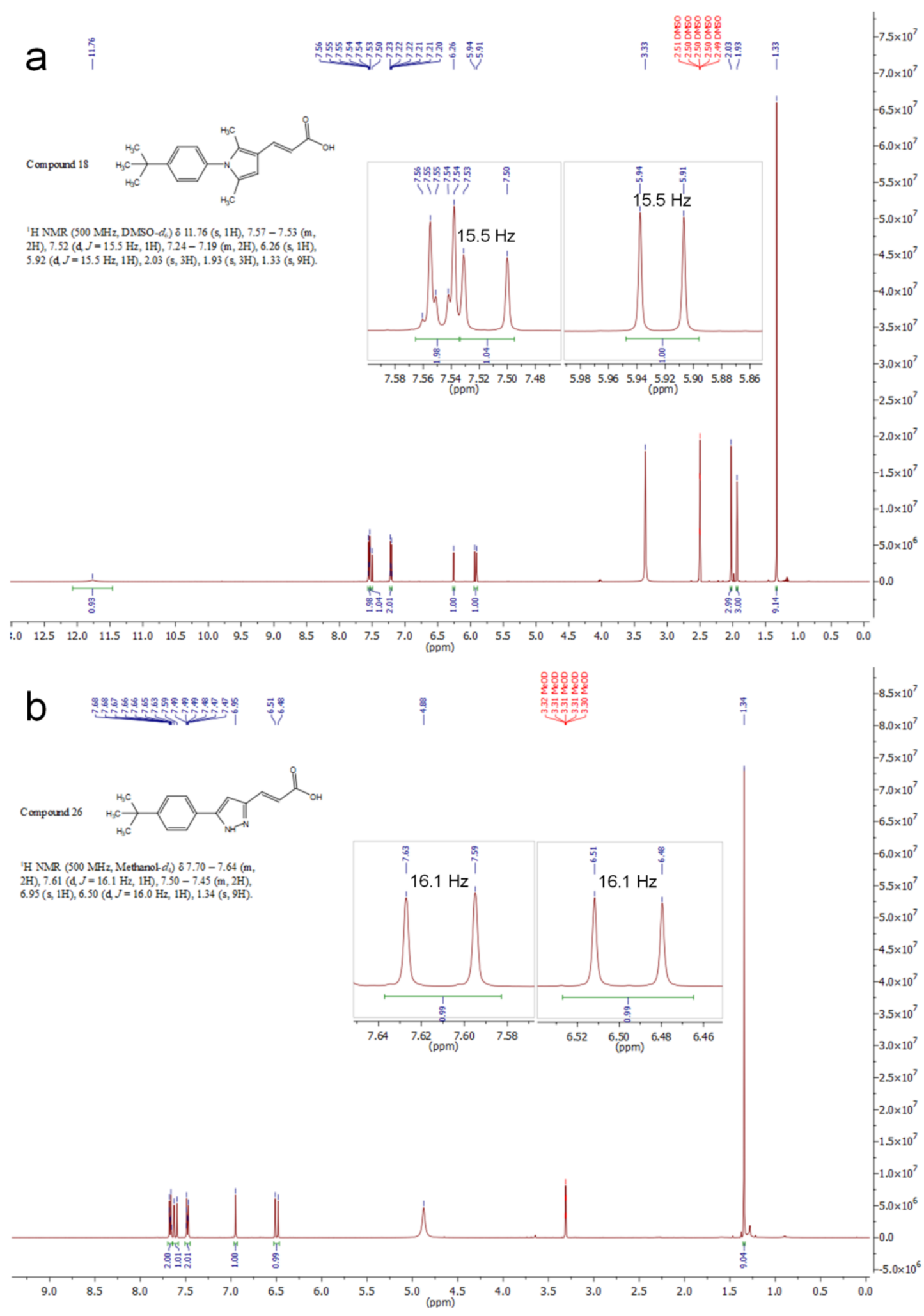

Figure S2. ${ }^{1} \mathrm{H}-\mathrm{NMR}$ spectra of acrylic acid derivatives 18 (a) and 26 (b) demonstrate Econfiguration as observed by coupling constants of $15.5-16.1 \mathrm{~Hz}$ for alkene protons. These large vicinal coupling constants across the double bonds suggest a large torsion angle $\left(\phi=180^{\circ}\right)$ and hence E-configuration of 18 and $26 .^{1}$ 

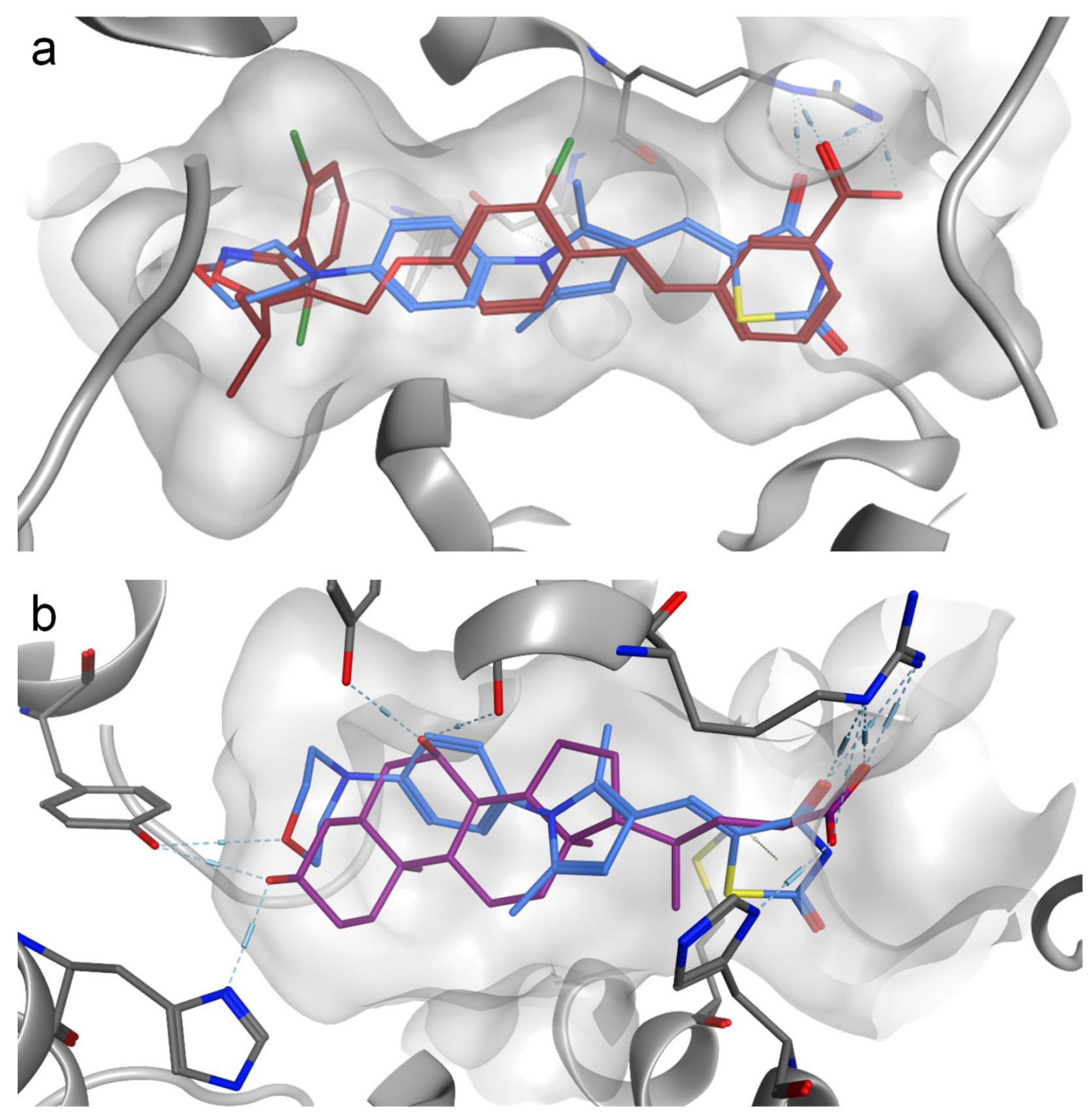

Figure S3. Molecular docking of $\mathbf{1 4}$ (blue) to the ligand binding sites of the FXR co-crystal structures in complex with GW4064 (1, a, red, pdb ID: 3dct) and CDCA (b, purple, pdb ID: 4qe6). 


\section{Experimental Procedures}

\section{Chemistry}

General. All chemicals and solvents were of reagent grade and used without further purification unless otherwise specified. All reactions were conducted in oven-dried glassware under argon atmosphere and in absolute solvents. NMR spectra were recorded on Bruker AM 250 XP, AV300, AV400 or AV500 spectrometers (Bruker Corporation, Billerica, MA, USA). Chemical shifts $(\delta)$ are reported in ppm relative to tetramethylsilane (TMS) as reference, coupling constants $(\mathcal{J})$ in hertz $(\mathrm{Hz})$. Multiplicity is reported as follows: s, singlet; $d$, doublet; dd, doublet of doublets; t, triplet; $q$, quartet and $\mathrm{m}$, multiplet. Mass spectra were obtained on a VG Platform II (Thermo Fischer Scientific, Inc., Waltham, MA, USA) using electrospray ionization (ESI). High resolution mass spectra were recorded on a MALDI LTQ ORBITRAP XL instrument (Thermo Fisher Scientific). Some compounds were purified by preparative HPLC using a Shimadzu preparative LC-20A Prominence (Shimadzu, Kyoto, Japan) with the following conditions: column, Luna (10 $\mu \mathrm{C} 18(2)$ $100 \AA ; 250 \mathrm{~mm} \times 21.2 \mathrm{~mm}$; Phenomenex, Torrance, CA, USA); mobile phase, linear gradient from $\mathrm{H}_{2} \mathrm{O}+0.1 \%$ formic acid/acetonitrile $50: 50$ to $90: 10$ within $10 \mathrm{~min}, 90: 10$ for $5 \mathrm{~min}$, linear gradient from 90:10 to 50:50 within 1 min and 50:50 for additional 5 min with UV-detection at 245 and 280 $\mathrm{nm}$. Compound purity was analyzed on a Waters 600 controller HPLC (Waters, Milford, MA, USA) equipped with a Waters 2487 dual absorbance detector and a Waters 717 Plus autosampler or on a VWR Chromaster (VWR, Radnor, PA, USA) equipped with a 5160 pump system, a DAD 5430, a 5260 autosampler, and a MultoHigh100 RP18-5 $250 \mathrm{~mm} \times 4 \mathrm{~mm}$ column (CSChromatographie Service $\mathrm{GmbH}$, Langerwehe, Germany) using a gradient $\left(\mathrm{H}_{2} \mathrm{O}+0.1 \%\right.$ formic acid/MeOH 80:20 isocratic for 5 min to $\mathrm{MeOH}$ after additional $45 \mathrm{~min}$ and $\mathrm{MeOH}$ for additional 10 $\mathrm{min})$ at a flow rate of $1 \mathrm{~mL} / \mathrm{min}$ or a gradient $\left(\mathrm{H}_{2} \mathrm{O}+0.1 \%\right.$ formic acid/MeOH 60:40 isocratic for 5 min to $\mathrm{MeOH}$ after additional $25 \mathrm{~min}$ and $\mathrm{MeOH}$ for additional $10 \mathrm{~min}$ ) at a flow rate of $1 \mathrm{~mL} / \mathrm{min}$ with UV-detection at 245 and $280 \mathrm{~nm}$. Only compounds with a purity of $\geq 95 \%$ according to the AUC at UV 245 and $280 \mathrm{~nm}$ detection were used for biological testing. 


\section{General procedures}

\section{General procedure A: Pyrrole synthesis}

The respective aniline derivative (27-38, $1.2 \mathrm{eq})$ and $p$-toluene sulfonic acid monohydrate $(0.1 \mathrm{eq})$ were dissolved in toluene $(2.5 \mathrm{~mL} / \mathrm{mmol})$. Subsequently, 2,5-hexanedione (39, $1.0 \mathrm{eq})$ was added, and the mixture was stirred for 16 hours at $110^{\circ} \mathrm{C}$. Afterwards the solvent was removed in vacuo. Further purification was performed by column chromatography.

\section{General procedure B: Formylation of pyrrole derivatives}

Phosphoryl chloride (2.7 eq) was dissolved in DMF $(14 \mathrm{~mL} / \mathrm{mmol})$ and cooled to $0{ }^{\circ} \mathrm{C}$ for $30 \mathrm{~min}$. The mixture was allowed to warm to room temperature, the respective pyrrole derivative (40-51, $1.0 \mathrm{eq}$ ) was added, and the mixture was stirred for one hour at room temperature. The mixture was then cooled to $0^{\circ} \mathrm{C}$ again and quenched with an equal volume $\mathrm{NaOH}$ solution $(1 \mathrm{M})$. Phases were separated and the aqueous layer was extracted with $\mathrm{CH}_{2} \mathrm{Cl}_{2}(3 \times 15 \mathrm{~mL})$. The combined organic layers were dried over $\mathrm{Na}_{2} \mathrm{SO}_{4}$ and the solvents were removed in vacuo. Further purification was performed by column chromatography.

\section{General procedure C: Knoevenagel reaction with pyrrole carbaldehydes}

The respective pyrrole carbaldehyde derivative (52-63, 1.0 eq) and thiazolidine-2,4-dione (64, $1.0 \mathrm{eq})$ were dissolved in toluene $(8 \mathrm{~mL} / \mathrm{mmol})$. Piperidine $(0.1 \mathrm{~mL} / \mathrm{mmol})$ was added and the mixture was heated to $110^{\circ} \mathrm{C}$. Once the temperature was reached the mixture was allowed to cool to room temperature slowly, whereby the respective crude product precipitated as yellow solid. Further purification was performed by filtration and washing with ice cold toluene. 
Synthesis of 6-26 and their precursors

Overview of compound numbering for thiazolidinediones 6-17 and precursors

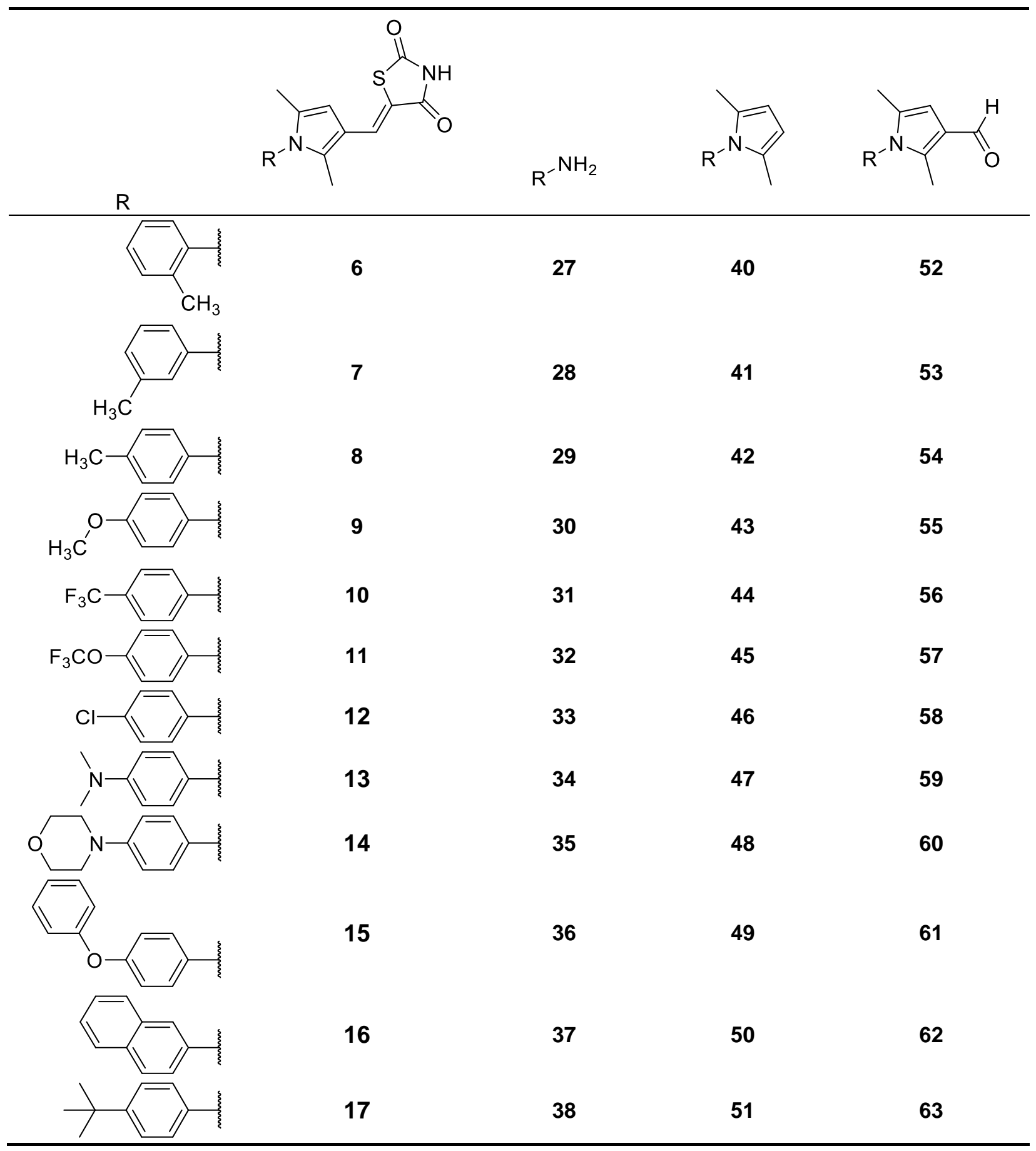


(Z)-5-[(2,5-Dimethyl-1-(2-methylphenyl)-1H-pyrrol-3-yl)methylene]thiazolidine-2,4-dione (6): Preparation according to general procedure $\mathrm{C}$ using 2,5-dimethyl-1-(2-methylphenyl)-1 $\mathrm{H}$-pyrrole3-carbaldehyde $(52,0.25 \mathrm{~g}, 1.2 \mathrm{mmol}, 1.0 \mathrm{eq})$ and thiazolidine-2,4-dione $(\mathbf{6 4}, 0.14 \mathrm{~g}, 1.2 \mathrm{mmol}$, $1.0 \mathrm{eq})$. Further purification was performed by column chromatography with hexane/EtOAc (4:1) as mobile phase to obtain 6 as a yellow solid $(85 \mathrm{mg}, 23 \%) . \mathrm{R}_{\mathrm{f}}($ hexane/EtOAc $=4: 1)=0.29 .{ }^{1} \mathrm{H}$ $\operatorname{NMR}\left(500 \mathrm{MHz}\right.$, DMSO- $\left.d_{6}\right): \delta=12.20(\mathrm{~s}, 1 \mathrm{H}), 7.68(\mathrm{~s}, 1 \mathrm{H}), 7.48-7.37(\mathrm{~m}, 4 \mathrm{H}), 6.20(\mathrm{~s}, 1 \mathrm{H}), 2.01$ (s, 3H), $1.89(\mathrm{~s}, 3 \mathrm{H}), 1.88(\mathrm{~s}, 3 \mathrm{H})$ ppm. ${ }^{13} \mathrm{C}-\mathrm{NMR}\left(126 \mathrm{MHz}\right.$, DMSO-d $\left.d_{6}\right): \delta=168.37,167.57$, 136.00, 135.86, 135.65, 131.11, 131.10, 129.46, 128.33, 127.33, 126.26, 114.69, 114.62, 104.71, 16.62, 12.09, 10.32 ppm. HRMS (MALDI): $\mathrm{m} / z$ calculated 313.10050 for $\mathrm{C}_{17} \mathrm{H}_{17} \mathrm{~N}_{2} \mathrm{O}_{2} \mathrm{~S}$, found $313.09975\left([\mathrm{M}+\mathrm{H}]^{+}\right)$.

(Z)-5-[(2,5-Dimethyl-1-(3-methylphenyl)-1H-pyrrol-3-yl)methylene]thiazolidine-2,4-dione (7): Preparation according to general procedure $\mathrm{C}$ using 2,5-dimethyl-1-(3-methylphenyl)-1 $\mathrm{H}$-pyrrole3-carbaldehyde $(53,0.30 \mathrm{~g}, 1.4 \mathrm{mmol}, 1.0 \mathrm{eq})$ and thiazolidine-2,4-dione $(64,0.16 \mathrm{~g}, 1.4 \mathrm{mmol}$, $1.0 \mathrm{eq})$. Further purification was performed by column chromatography with hexane/EtOAc (4:1) as mobile phase to obtain 7 as a yellow solid $(0.12 \mathrm{~g}, 27 \%) . R_{f}($ hexane/EtOAc $=4: 1)=0.16$. ${ }^{1} \mathrm{H}-\mathrm{NMR}\left(500 \mathrm{MHz}\right.$, DMSO- $\left.d_{6}\right): \delta=12.19(\mathrm{~s}, 1 \mathrm{H}), 7.65(\mathrm{~s}, 1 \mathrm{H}), 7.45(\mathrm{t}, J=7.7 \mathrm{~Hz}, 1 \mathrm{H}), 7.33(\mathrm{~d}, J$ $=7.6 \mathrm{~Hz}, 1 \mathrm{H}), 7.15-7.10(\mathrm{~m}, 2 \mathrm{H}), 6.16(\mathrm{~s}, 1 \mathrm{H}), 2.38(\mathrm{~s}, 3 \mathrm{H}), 2.11(\mathrm{~s}, 3 \mathrm{H}), 1.98(\mathrm{~s}, 3 \mathrm{H}) \mathrm{ppm}$. ${ }^{13} \mathrm{C}-\mathrm{NMR}\left(126 \mathrm{MHz}\right.$, DMSO- $\left.d_{6}\right): \delta=168.32,167.53,139.32,136.80,135.83,131.51,129.44$, 129.34, 128.23, 126.23, 124.82, 114.72, 104.85, 104.82, 20.74, 12.50, 10.71 ppm. HRMS (MALDI): $\mathrm{m} / z$ calculated 312.09270 for $\mathrm{C}_{17} \mathrm{H}_{16} \mathrm{~N}_{2} \mathrm{O}_{2} \mathrm{~S}$, found $312.09273\left([\mathrm{M}]^{++}\right)$.

(Z)-5-[(2,5-Dimethyl-1-(4-methylphenyl)-1H-pyrrol-3-yl)methylene]thiazolidine-2,4-dione (8): Preparation according to general procedure $\mathrm{C}$ using 2,5-dimethyl-1-(4-methylphenyl)-1 $\mathrm{H}$-pyrrole3-carbaldehyde $(54,0.26 \mathrm{~g}, 1.2 \mathrm{mmol}, 1.0 \mathrm{eq})$ and thiazolidine-2,4-dione $(64,0.14 \mathrm{~g}, 1.2 \mathrm{mmol}$, 1.0 eq). Further purification was performed by column chromatography with $\mathrm{CH}_{2} \mathrm{Cl}_{2} / \mathrm{MeOH}$ (98:2) as mobile phase to obtain 8 as a yellow solid $(0.18 \mathrm{~g}, 48 \%) . \mathrm{R}_{\mathrm{f}}\left(\mathrm{CH}_{2} \mathrm{Cl}_{2} / \mathrm{MeOH}=98: 2\right)=0.83$. ${ }^{1} \mathrm{H}-\mathrm{NMR}\left(500 \mathrm{MHz}, \mathrm{DMSO}-d_{6}\right): \delta=12.20(\mathrm{~s}, 1 \mathrm{H}), 7.66(\mathrm{~s}, 1 \mathrm{H}), 7.38-7.34(\mathrm{~m}, 2 \mathrm{H}), 7.23-7.19(\mathrm{~m}$, $2 \mathrm{H}), 6.16(\mathrm{~s}, 1 \mathrm{H}), 2.40(\mathrm{~s}, 3 \mathrm{H}), 2.10(\mathrm{~s}, 3 \mathrm{H}), 1.97(\mathrm{~s}, 3 \mathrm{H}) \mathrm{ppm} .{ }^{13} \mathrm{C}-\mathrm{NMR}\left(126 \mathrm{MHz}\right.$, DMSO- $\left.d_{6}\right): \delta$ $=168.31,167.49,138.34,135.96,134.28,131.61,130.08,127.57,126.28,114.68,114.63$, 104.79, 20.69, 12.49, 10.69 ppm. HRMS (MALDI): $\mathrm{m} / \mathrm{z}$ calculated 312.09270 for $\mathrm{C}_{17} \mathrm{H}_{16} \mathrm{~N}_{2} \mathrm{O}_{2} \mathrm{~S}$, found $312.09250\left([\mathrm{M}]^{+}\right)$.

\section{(Z)-5-[1-(4-Methoxyphenyl)-2,5-dimethyl-1 H-pyrrol-3-yl)methylene]thiazolidine-2,4-dione}

(9): Preparation according to general procedure $\mathrm{C}$ using 1-(4-methoxyphenyl)-2,5-dimethyl-1 $\mathrm{H}$ pyrrole-3-carbaldehyde $(\mathbf{5 5}, 0.29 \mathrm{~g}, 1.3 \mathrm{mmol}, 1.0 \mathrm{eq})$ and thiazolidine-2,4-dione $(\mathbf{6 4}, 0.15 \mathrm{~g}$, $1.3 \mathrm{mmol}, 1.0 \mathrm{eq}$ ). Further purification was performed by column chromatography with $\mathrm{CH}_{2} \mathrm{Cl}_{2} / \mathrm{MeOH}$ (98:2) as mobile phase to obtain 9 as a yellow solid $(0.30 \mathrm{~g}, 63 \%)$. $\mathrm{R}_{\mathrm{f}}$ $\left(\mathrm{CH}_{2} \mathrm{Cl}_{2} / \mathrm{MeOH}=98: 2\right)=0.48 .{ }^{1} \mathrm{H}-\mathrm{NMR}\left(500 \mathrm{MHz}\right.$, DMSO- $\left.d_{6}\right): \delta=12.17(\mathrm{~s}, 1 \mathrm{H}), 7.66(\mathrm{~s}, 1 \mathrm{H})$, 7.29-7.19 (m, 2H), 7.13-7.03 (m, 2H), $6.14(\mathrm{~s}, 1 \mathrm{H}), 3.82(\mathrm{~s}, 3 \mathrm{H}), 2.09(\mathrm{~s}, 3 \mathrm{H}), 1.97(\mathrm{~s}, 3 \mathrm{H}) \mathrm{ppm}$. 
${ }^{13} \mathrm{C}-\mathrm{NMR}\left(126 \mathrm{MHz}\right.$, DMSO- $\left.d_{6}\right): \delta=168.32,167.49,159.17,136.24,131.82,129.45,128.98$, 126.34, 114.67, 114.57, 114.51, 104.63, 55.41, 12.47, 10.69 ppm. HRMS (MALDI): $\mathrm{m} / \mathrm{z}$ calculated 328.08761 for $\mathrm{C}_{17} \mathrm{H}_{16} \mathrm{~N}_{2} \mathrm{O}_{3} \mathrm{~S}$, found $328.08769\left([\mathrm{M}]^{+\cdot}\right)$.

(Z)-5-[1-(4-Trifluoromethylphenyl)-2,5-dimethyl-1 H-pyrrol-3-yl)methylene]thiazolidine-2,4-

dione (10): Preparation according to general procedure $C$ using 1-(4-trifluoromethylphenyl)-2,5dimethyl-1 $H$-pyrrole-3-carbaldehyde $(56,90 \mathrm{mg}, 0.34 \mathrm{mmol}, 1.0 \mathrm{eq})$ and thiazolidine-2,4-dione (64, $40 \mathrm{mg}, 0.34 \mathrm{mmol}, 1.0 \mathrm{eq})$. Further purification was performed by washing with saturated ammonium chloride solution and afterwards by crystallization from ethyl acetate and hexane to obtain 10 as a yellow solid (32 mg, 26\%). $\mathrm{R}_{\mathrm{f}}\left(\mathrm{CH}_{2} \mathrm{Cl}_{2} / \mathrm{MeOH}=98: 2\right)=0.36 .{ }^{1} \mathrm{H}-\mathrm{NMR}(500 \mathrm{MHz}$, DMSO- $\left.d_{6}\right): \delta=12.25(\mathrm{~s}, 1 \mathrm{H}), 7.97-7.93(\mathrm{~m}, 2 \mathrm{H}), 7.67(\mathrm{~s}, 1 \mathrm{H}), 7.65-7.61(\mathrm{~m}, 2 \mathrm{H}), 6.22(\mathrm{~s}, 1 \mathrm{H}), 2.14$ (s, 3H), 2.02 (s, 3H) ppm. ${ }^{13} \mathrm{C}-N M R\left(126 \mathrm{MHz}\right.$, DMSO- $\left.d_{6}\right): \delta=168.22,167.47,140.46,135.61$, 131.45, 129.07 (q, $J=32.3 \mathrm{~Hz}$ ), 129.01, 126.71 (q, $J=3.3 \mathrm{~Hz}), 125.92,123.90$ (q, $J=272.9 \mathrm{~Hz}$ ), $115.51,115.23,105.44,12.48,10.74$ ppm. HRMS (MALDI): $\mathrm{m} / z$ calculated 367.07226 for $\mathrm{C}_{17} \mathrm{H}_{14} \mathrm{~F}_{3} \mathrm{~N}_{2} \mathrm{O}_{2} \mathrm{~S}$, found $367.07121\left([\mathrm{M}+\mathrm{H}]^{+}\right)$.

\section{(Z)-5-[1-(4-Trifluoromethoxyphenyl)-2,5-dimethyl-1 H-pyrrol-3-yl)methylene]thiazolidine-}

2,4-dione (11): Preparation according to general procedure $\mathrm{C}$ using 1-(4-trifluoromethoxyphenyl)2,5-dimethyl- $1 \mathrm{H}$-pyrrole-3-carbaldehyde $(57,0.28 \mathrm{~g}, 1.0 \mathrm{mmol}, 1.0 \mathrm{eq})$ and thiazolidine-2,4-dione $(64,0.12 \mathrm{~g}, 1.0 \mathrm{mmol}, 1.0 \mathrm{eq})$. Further purification was performed by washing with saturated ammonium chloride solution and afterwards by crystallization from ethyl acetate to obtain 11 as a yellow solid (94 mg, 19\%). $\mathrm{R}_{\mathrm{f}}\left(\mathrm{CH}_{2} \mathrm{Cl}_{2} / \mathrm{MeOH}=98: 2\right)=0.39 .{ }^{1} \mathrm{H}-\mathrm{NMR}\left(500 \mathrm{MHz}, \mathrm{DMSO}-d_{6}\right): \delta=$ $12.23(\mathrm{~s}, 1 \mathrm{H}), 7.66(\mathrm{~s}, 1 \mathrm{H}), 7.65-7.62(\mathrm{~m}, 2 \mathrm{H}), 7.42-7.39(\mathrm{~m}, 2 \mathrm{H}), 6.18(\mathrm{~s}, 1 \mathrm{H}), 2.12(\mathrm{~s}, 3 \mathrm{H}), 2.00$ (s, 3H) ppm. ${ }^{13} \mathrm{C}-\mathrm{NMR}\left(126 \mathrm{MHz}\right.$, DMSO- $\left.d_{6}\right): \delta=168.33,167.57,148.14,135.89,135.86,131.62$, 130.12, 126.07, 122.13, 120.05 (q, $J=257.4$ Hz), 115.26, 114.98, 105.14, 12.51, 10.78 ppm. HRMS (MALDI): $m / z$ calculated 382.05935 for $\mathrm{C}_{17} \mathrm{H}_{13} \mathrm{~F}_{3} \mathrm{~N}_{2} \mathrm{O}_{3} \mathrm{~S}$, found $382.05880\left([\mathrm{M}]^{+}\right.$).

\section{(Z)-5-[1-(4-Chlorophenyl)-2,5-dimethyl-1 H-pyrrol-3-yl)methylene]thiazolidine-2,4-dione}

(12): Preparation according to general procedure $\mathrm{C}$ using 1-(4-chlorophenyl)-2,5-dimethyl-1 $\mathrm{H}$ pyrrole-3-carbaldehyde $(\mathbf{5 8}, 0.33 \mathrm{~g}, 1.4 \mathrm{mmol}, 1.0 \mathrm{eq})$ and thiazolidine-2,4-dione $(\mathbf{6 4}, 0.16 \mathrm{~g}$, $1.4 \mathrm{mmol}, 1.0 \mathrm{eq})$. Further purification was performed by column chromatography with $\mathrm{CH}_{2} \mathrm{Cl}_{2} / \mathrm{MeOH}$ (98:2) as mobile phase to obtain 12 as a yellow solid (43 mg, 45\%). $\mathrm{R}_{\mathrm{f}}$ $\left(\mathrm{CH}_{2} \mathrm{Cl}_{2} / \mathrm{MeOH}=98: 2\right)=0.25 .{ }^{1} \mathrm{H}-\mathrm{NMR}\left(500 \mathrm{MHz}, \mathrm{DMSO}-d_{6}\right): \delta=12.23(\mathrm{~s}, 1 \mathrm{H}), 7.66(\mathrm{~s}, 1 \mathrm{H})$, 7.65-7.61 (m, 2H), 7.42-7.38 (m, 2H), $6.18(\mathrm{~s}, 1 \mathrm{H}), 2.12(\mathrm{~s}, 3 \mathrm{H}), 2.00(\mathrm{~s}, 3 \mathrm{H})$ ppm. ${ }^{13} \mathrm{C}-\mathrm{NMR}$ $\left(126 \mathrm{MHz}\right.$, DMSO- $\left.d_{6}\right): \delta=168.26,167.48,135.78,135.73,133.43,131.52,129.80,129.62$, 126.05, 115.14, 114.97, 105.11, 12.44, 10.68 ppm. HRMS (MALDI): $\mathrm{m} / \mathrm{z}$ calculated 333.04590 for $\mathrm{C}_{16} \mathrm{H}_{14} \mathrm{CIN}_{2} \mathrm{O}_{2} \mathrm{~S}$, found $333.04536\left([\mathrm{M}+\mathrm{H}]^{+}\right)$.

(Z)-5-[(1-(4-Dimethylaminophenyl)-2,5-dimethyl-1H-pyrrol-3-yl)methylene]thiazolidine-2,4dione (13): Preparation according to general procedure C using 1-(4-dimethylaminophenyl)-2,5- 
dimethyl-1 $H$-pyrrole-3-carbaldehyde $(59,0.23 \mathrm{~g}, 0.95 \mathrm{mmol}, 1.0 \mathrm{eq})$ and thiazolidine-2,4-dione $(64,0.11 \mathrm{~g}, 0.95 \mathrm{mmol}, 1.0 \mathrm{eq})$. Further purification was performed by column chromatography with $\mathrm{CH}_{2} \mathrm{Cl}_{2} / \mathrm{MeOH}$ (98:2) as mobile phase to obtain 13 as a yellow solid (75 mg, 23\%). $\mathrm{R}_{\mathrm{f}}$ $\left(\mathrm{CH}_{2} \mathrm{Cl}_{2} / \mathrm{MeOH}=98: 2\right)=0.39 .{ }^{1} \mathrm{H}-\mathrm{NMR}\left(500 \mathrm{MHz}\right.$, DMSO- $\left.d_{6}\right): \delta=12.15(\mathrm{~s}, 1 \mathrm{H}), 7.65(\mathrm{~s}, 1 \mathrm{H})$, 7.11-7.04 (m, 2H), 6.84-6.76 (m, 2H), $6.12(\mathrm{~s}, 1 \mathrm{H}), 2.96(\mathrm{~s}, 6 \mathrm{H}), 2.09(\mathrm{~s}, 3 \mathrm{H}), 1.96(\mathrm{~s}, 3 \mathrm{H}) \mathrm{ppm}$. ${ }^{13} \mathrm{C}-\mathrm{NMR}\left(126 \mathrm{MHz}\right.$, DMSO- $\left.d_{6}\right): \delta=168.65,167.78,150.24,136.88,132.33,128.29,126.80$, 125.14, 114.49, 114.15, 112.44, 104.55, 40.15, 12.71, 10.90 ppm. HRMS (MALDI): $m / z$ calculated 342.12707 for $\mathrm{C}_{18} \mathrm{H}_{20} \mathrm{~N}_{3} \mathrm{O}_{2} \mathrm{~S}$, found $342.12670\left([\mathrm{M}+\mathrm{H}]^{+}\right)$.

\section{(Z)-5-[(2,5-Dimethyl-1-(4-(4-morpholinyl)phenyl)-1 H-pyrrol-3-yl)methylene]thiazolidine-2,4-}

dione (14): Preparation according to general procedure C using 2,5-dimethyl-1-(4-(4morpholinyl)phenyl)-1H-pyrrole-3-carbaldehyde $(60,0.10 \mathrm{~g}, 0.35 \mathrm{mmol}, 1.0 \mathrm{eq})$ and thiazolidine2,4-dione (64, $41 \mathrm{mg}, 0.35 \mathrm{mmol}, 1.0 \mathrm{eq}$ ). Further purification was performed by washing with saturated ammonium chloride solution and afterwards by column chromatography with $\mathrm{CH}_{2} \mathrm{Cl}_{2} / \mathrm{MeOH}$ (98:2) as mobile phase to obtain 14 as a yellow solid $(0.10 \mathrm{~g}, 75 \%)$. $\mathrm{R}_{\mathrm{f}}$ $\left(\mathrm{CH}_{2} \mathrm{Cl}_{2} / \mathrm{MeOH}=98: 2\right)=0.60 .{ }^{1} \mathrm{H}-\mathrm{NMR}\left(500 \mathrm{MHz}, \mathrm{DMSO}-d_{6}\right): \delta=12.18(\mathrm{~s}, 1 \mathrm{H}), 7.65(\mathrm{~s}, 1 \mathrm{H})$, 7.17-7.14 (m, 2H), 7.08-7.05 (m, 2H), $6.13(\mathrm{~s}, 1 \mathrm{H}), 3.75(\mathrm{t}, \mathrm{J}=4.6 \mathrm{~Hz}, 4 \mathrm{H}), 3.20$ (t, J = $4.8 \mathrm{~Hz}$, 4H), 2.10 (s, 3H), 1.97 (s, 3H) ppm. ${ }^{13} \mathrm{C}-\mathrm{NMR}\left(126 \mathrm{MHz}\right.$, DMSO- $\left.d_{6}\right): \delta=168.39,167.59,150.79$, 136.40, 131.95, 128.29, 127.66, 126.41, 115.06, 114.47, 114.33, 104.54, 66.07, 47.76, 12.57, 10.76 ppm. HRMS (MALDI): $\mathrm{m} / \mathrm{z}$ calculated 384.13764 for $\mathrm{C}_{20} \mathrm{H}_{22} \mathrm{~N}_{3} \mathrm{O}_{3} \mathrm{~S}$, found 384.13610 $\left([\mathrm{M}+\mathrm{H}]^{+}\right)$.

\section{(Z)-5-[(2,5-Dimethyl-1-(4-phenoxyphenyl)-1H-pyrrol-3-yl)methylene]thiazolidine-2,4-dione}

(15): Preparation according to general procedure $\mathrm{C}$ using 2,5-dimethyl-1-(4-phenoxyphenyl)-1 $\mathrm{H}$ pyrrole-3-carbaldehyde $(61,0.25 \mathrm{~g}, 0.86 \mathrm{mmol}, 1.0 \mathrm{eq})$ and thiazolidine-2,4-dione $(64,0.10 \mathrm{~g}$, $0.86 \mathrm{mmol}, 1.0 \mathrm{eq})$. Further purification was performed by column chromatography with $\mathrm{CH}_{2} \mathrm{Cl}_{2} / \mathrm{MeOH}$ (98:2) as mobile phase to obtain 15 as a yellow solid $(0.13 \mathrm{~g}, 41 \%)$. $\mathrm{R}_{\mathrm{f}}$ $\left(\mathrm{CH}_{2} \mathrm{Cl}_{2} / \mathrm{MeOH}=98: 2\right)=0.44 .{ }^{1} \mathrm{H}-\mathrm{NMR}\left(500 \mathrm{MHz}, \mathrm{CDCl}_{3}\right): \delta=8.13(\mathrm{~s}, 1 \mathrm{H}), 7.85(\mathrm{~s}, 1 \mathrm{H}), 7.43-$ $7.39(\mathrm{~m}, 2 \mathrm{H}), 7.22-7.18(\mathrm{~m}, 1 \mathrm{H}), 7.14-7.08(\mathrm{~m}, 6 \mathrm{H}), 6.18(\mathrm{~s}, 1 \mathrm{H}), 2.18(\mathrm{~s}, 3 \mathrm{H}), 2.05(\mathrm{~s}, 3 \mathrm{H})$ ppm. ${ }^{13} \mathrm{C}-\mathrm{NMR}\left(126 \mathrm{MHz}, \mathrm{CDCl}_{3}\right): \delta=167.93,166.81,158.24,156.14,137.24,132.59,131.97$, 130.22, 129.29, 128.77, 124.53, 119.97, 118.86, 115.53, 114.04, 105.33, 12.98, 11.33 ppm. HRMS (MALDI): $m / z$ calculated 390.10326 for $\mathrm{C}_{22} \mathrm{H}_{18} \mathrm{~N}_{2} \mathrm{O}_{3} \mathrm{~S}$, found $390.10238\left([\mathrm{M}]^{+*}\right.$ ).

\section{(Z)-5-[(2,5-Dimethyl-1-(naphthalene-2-yl)-1 H-pyrrol-3-yl)methylene]thiazolidine-2,4-dione} (16): Preparation according to general procedure $\mathrm{C}$ using 2,5-dimethyl-1-(naphthalene-2-yl)-1 $\mathrm{H}$ pyrrole-3-carbaldehyde $(62,0.12 \mathrm{~g}, 0.48 \mathrm{mmol}, 1.0 \mathrm{eq})$ and thiazolidine-2,4-dione $(64,56 \mathrm{mg}$, $0.48 \mathrm{mmol}, 1.0 \mathrm{eq})$. Further purification was performed by column chromatography with $\mathrm{CH}_{2} \mathrm{Cl}_{2} / \mathrm{MeOH}$ (98:2) as mobile phase to obtain 16 as a yellow solid (32 mg, 18\%). $\mathrm{R}_{\mathrm{f}}$ $\left(\mathrm{CH}_{2} \mathrm{Cl}_{2} / \mathrm{MeOH}=98: 2\right)=0.63 .{ }^{1} \mathrm{H}-\mathrm{NMR}\left(500 \mathrm{MHz}\right.$, DMSO- $\left.d_{6}\right): \delta=12.23(\mathrm{~s}, 1 \mathrm{H}), 8.11(\mathrm{~d}$, $J=8.8 \mathrm{~Hz}, 1 \mathrm{H})$, 8.07-8.00 (m, 2H), 7.98-7.96 (m, 1H), $7.70(\mathrm{~s}, 1 \mathrm{H})$, 7.65-7.62 (m, 2H), 7.45 (dd, 
$J=8.6,2.1 \mathrm{~Hz}, 1 \mathrm{H}), 6.23(\mathrm{~s}, 1 \mathrm{H}), 2.17(\mathrm{~s}, 3 \mathrm{H}), 2.04(\mathrm{~s}, 3 \mathrm{H}) \mathrm{ppm} .{ }^{13} \mathrm{C}-\mathrm{NMR}\left(126 \mathrm{MHz}\right.$, DMSO- $\left.d_{6}\right)$ : $\delta=168.35,167.59,136.04,134.30,132.94,132.39,131.78,129.42,128.10,127.79,127.12$, 127.04, 126.56, 126.19, 125.58, 114.97, 114.91, 105.02, 12.57, 10.79 ppm. HRMS (MALDI): $\mathrm{m} / \mathrm{z}$ calculated 348.09270 for $\mathrm{C}_{20} \mathrm{H}_{16} \mathrm{~N}_{2} \mathrm{O}_{2} \mathrm{~S}$, found $348.09284\left([\mathrm{M}]^{+}\right)$.

\section{(Z)-5-[(1-(4-tert-Butyl)phenyl)-2,5-dimethyl-1 H-pyrrol-3-yl)methylene]thiazolidine-2,4-dione} (17): Preparation according to general procedure $C$ using 1-(1-(4-tert-butyl)phenyl)-4-yl-2,5dimethyl-1 $H$-pyrrole-3-carbaldehyde $(63,0.16 \mathrm{~g}, 0.63 \mathrm{mmol}, 1.0 \mathrm{eq})$ and thiazolidine-2,4-dione (64, $74 \mathrm{mg}, 0.63 \mathrm{mmol}, 1.0 \mathrm{eq})$. Further purification was performed by column chromatography with $\mathrm{CH}_{2} \mathrm{Cl}_{2} / \mathrm{MeOH}$ (98:2) as mobile phase to obtain 17 as a yellow solid (68 mg, 31\%). $\mathrm{R}_{\mathrm{f}}$ $\left(\mathrm{CH}_{2} \mathrm{Cl}_{2} / \mathrm{MeOH}=98: 2\right)=0.81 .{ }^{1} \mathrm{H}-\mathrm{NMR}\left(500 \mathrm{MHz}, \mathrm{DMSO}-d_{6}\right) \delta=12.20(\mathrm{~s}, 1 \mathrm{H}), 7.66(\mathrm{~s}, 1 \mathrm{H})$, 7.59-7.55 (m, 2H), 7.27-7.23 (m, 2H), $6.16(\mathrm{~s}, 1 \mathrm{H}), 2.10(\mathrm{~s}, 3 \mathrm{H}), 1.98(\mathrm{~s}, 3 \mathrm{H}), 1.34(\mathrm{~s}, 9 \mathrm{H}) \mathrm{ppm}$. ${ }^{13} \mathrm{C}-\mathrm{NMR}\left(126 \mathrm{MHz}\right.$, DMSO- $\left.d_{6}\right) \delta=168.32,167.48,151.19,136.06,134.26,131.69,127.35$, 126.35, 126.30, 114.68, 114.62, 104.82, 34.54, 31.08, 12.62, 10.85 ppm. HRMS (MALDI): m/z calculated 354.13965 for $\mathrm{C}_{20} \mathrm{H}_{22} \mathrm{~N}_{2} \mathrm{O}_{2} \mathrm{~S}$, found $354.13989\left([\mathrm{M}]^{++}\right)$.

(E)-3-[1-(4-tert-Butylphenyl)-2,5-dimethyl-1 H-pyrrol-3-yl]acrylic acid (18): Malonic acid (1.5 g, $14 \mathrm{mmol}, 2.5 \mathrm{eq}$ ) and $\beta$-alanine (98 mg, $1.1 \mathrm{mmol}, 0.20 \mathrm{eq}$ ) were dissolved in $22 \mathrm{~mL}$ pyridine and 1-(1-(4-tert-butyl)phenyl)-4-yl-2,5-dimethyl-1H-pyrrole-3-carbaldehyde (63, $1.4 \mathrm{~g}, 5.5 \mathrm{mmol}$, 1.0 eq.) was added. The mixture was heated to $90{ }^{\circ} \mathrm{C}$ for 2 hours. After cooling to room temperature the mixture was poured into iced water and acidified with aqueous hydrochloric acid $(10 \%, 50 \mathrm{~mL})$. The resulting precipitate was filtered and purified by column chromatography in a gradient of hexane/EtOAc (5:1 to $4: 1)$ to afford the product as a yellow solid (558 mg, 34\%). $R_{f}$ $\left(\mathrm{CH}_{2} \mathrm{Cl}_{2} / \mathrm{MeOH}=95: 5\right)=0.48 .{ }^{1} \mathrm{H}-\mathrm{NMR}\left(500 \mathrm{MHz}\right.$, DMSO- $\left.d_{6}\right): \delta=11.76(\mathrm{~s}, 1 \mathrm{H}), 7.56-7.53(\mathrm{~m}$, 2H), $7.52(\mathrm{~d}, J=15.5 \mathrm{~Hz}, 1 \mathrm{H}), 7.23-7.20(\mathrm{~m}, 2 \mathrm{H}), 6.26(\mathrm{~s}, 1 \mathrm{H}), 5.92(\mathrm{~d}, J=15.5 \mathrm{~Hz}, 1 \mathrm{H}), 2.03(\mathrm{~s}$, 3H), 1.93 (s, 3H), 1.33 (s, 9H) ppm. ${ }^{13} \mathrm{C}-N M R(126 \mathrm{MHz}$, DMSO-d $): \delta=168.54,150.75,137.64$, 134.69, 132.37, 130.17, 127.45, 126.20, 116.05, 111.64, 104.11, 34.47, 31.09, 12.64, $10.59 \mathrm{ppm}$. HRMS (MALDI): $m / z$ calculated 298.18016 for $\mathrm{C}_{19} \mathrm{H}_{24} \mathrm{NO}_{2}$, found $298.17917\left([\mathrm{M}+\mathrm{H}]^{+}\right)$.

3-[1-(4-tert-Butylphenyl)-2,5-dimethyl-1H-pyrrol-3-yl]propanoic acid (19): Acrylic acid derivative 18 (500 mg, $1.68 \mathrm{mmol}, 1.00 \mathrm{eq}$ ) was dissolved in $100 \mathrm{~mL}$ methanol and $\mathrm{PtO}_{2}(381 \mathrm{mg}$, $1.68 \mathrm{mmol}, 1.00 \mathrm{eq}$ ) was added. The flask was flushed with argon three times and then once with hydrogen. The suspension was stirred under hydrogen atmosphere at ambient temperature for 18 hours. The resulting mixture was filtered and the precipitate was washed with methanol. The solvent of the filtrate was removed in vacuo and the crude product was purified by column chromatography in a gradient of hexane/acetone (9:1 to $4: 1)$. Subsequently, the product containing fractions were further purified by column chromatography in degassed $\mathrm{CH}_{2} \mathrm{Cl}_{2} / \mathrm{MeOH}$ (98:2) under argon atmosphere to afford the product as a yellow solid $(15 \mathrm{mg}, 3 \%)$. $\mathrm{R}_{\mathrm{f}}$ $\left(\mathrm{CH}_{2} \mathrm{Cl}_{2} / \mathrm{MeOH}=95: 5\right)=0.34 .{ }^{1} \mathrm{H}-\mathrm{NMR}\left(500 \mathrm{MHz}, \mathrm{MeOD}-\mathrm{d}_{4}\right): \delta=7.53-7.49(\mathrm{~m}, 2 \mathrm{H}), 7.11-7.07$ (m, 2H), $5.73(\mathrm{~s}, 1 \mathrm{H}), 2.69(\mathrm{t}, J=7.6 \mathrm{~Hz}, 2 \mathrm{H}), 2.48(\mathrm{t}, J=7.6 \mathrm{~Hz}, 2 \mathrm{H}), 1.94(\mathrm{~s}, 3 \mathrm{H}), 1.91(\mathrm{~s}, 3 \mathrm{H})$, 
$1.37(\mathrm{~s}, 9 \mathrm{H}) \mathrm{ppm} .{ }^{13} \mathrm{C}-\mathrm{NMR}\left(126 \mathrm{MHz}, \mathrm{MeOD}-d_{4}\right): \delta=177.65,151.83,138.04,128.99,128.58$, 127.06, 125.39, 118.53, 107.15, 36.97, 35.52, 31.79, 22.94, 12.93, 10.66 ppm. HRMS (MALDI): $\mathrm{m} / z$ calculated 300.19581 for $\mathrm{C}_{19} \mathrm{H}_{26} \mathrm{NO}_{2}$, found $300.19563\left([\mathrm{M}+\mathrm{H}]^{+}\right)$.

1-(4-tert-Butylphenyl)-2,5-dimethyl-1H-pyrrole-3-carboxylic acid (20): To a mixture of 1-(1-(4tert-butyl)phenyl)-4-yl-2,5-dimethyl-1 $H$-pyrrole-3-carbaldehyde $(63,0.10 \mathrm{~g}, 0.39 \mathrm{mmol}, 1.0 \mathrm{eq}$.) in $3 \mathrm{~mL}$ acetone at $0{ }^{\circ} \mathrm{C}$ was added dropwise a solution of $\mathrm{KMnO}_{4}(0.10 \mathrm{~g}, 0.66 \mathrm{mmol}, 1.7 \mathrm{eq}$. $)$ in 0.4 $\mathrm{mL}$ water and $2.6 \mathrm{~mL}$ acetone. While stirring, the resulting mixture was allowed to warm to room temperature and stirred for 18 hours. The mixture was filtered, and the precipitate was rinsed with acetone. The solvent of the filtrate was removed in vacuo, aqueous $\mathrm{NaOH}$ solution ( $1 \mathrm{M}, 20 \mathrm{~mL}$ ) was added and the aqueous layer was washed with ethyl acetate $(4 \times 20 \mathrm{~mL})$. The aqueous layer was then acidified with aqueous hydrochloric acid $(10 \%, 10 \mathrm{~mL})$ and extracted with ethyl acetate $\left(4 \times 25 \mathrm{~mL}\right.$ ). The latter organic layers were combined, dried over $\mathrm{Na}_{2} \mathrm{SO}_{4}$ and the solvents were evaporated in vacuo. The crude product was purified by column chromatography in a gradient of hexane/EtOAc (4:1 to $2: 1)$ to afford the title compound as a yellow solid $(21 \mathrm{mg}, 20 \%)$. $R_{f}$ (hexane/EtOAc $=4: 1)=0.54 .{ }^{1} \mathrm{H}-\mathrm{NMR}\left(400 \mathrm{MHz}, \mathrm{MeOD}-\mathrm{d}_{4}\right)$ : $\delta=7.61-7.57(\mathrm{~m}, 2 \mathrm{H}), 7.17-7.13(\mathrm{~m}$, 2H), 6.30 (s, 1H), $2.23(\mathrm{~s}, 3 \mathrm{H}), 1.95(\mathrm{~s}, 3 \mathrm{H}), 1.39$ (s, 9H) ppm. ${ }^{13} \mathrm{C}-\mathrm{NMR}\left(126 \mathrm{MHz}, \mathrm{MeOD}-d_{4}\right): \delta$ $=169.37,153.15,137.70,136.48,130.10,128.89,127.54,112.27,108.90,35.65,31.72,12.72$, 12.65 ppm. HRMS (MALDI): $m / z$ calculated 272.16451 for $\mathrm{C}_{17} \mathrm{H}_{22} \mathrm{NO}_{2}$, found $272.16349\left([\mathrm{M}+\mathrm{H}]^{+}\right)$.

3-[5-(4-tert-Butylphenyl)-4-methyloxazol-2-yl]propanoic acid (21): A solution of lithium hydroxide monohydrate (19 mg, $0.45 \mathrm{mmol}, 3.0 \mathrm{eq}$ ) in $5 \mathrm{~mL}$ water was added to a solution of the ester 67 ( $45 \mathrm{mg}, 0.15 \mathrm{mmol}, 1.0 \mathrm{eq}$ ) in $5 \mathrm{~mL} \mathrm{EtOH}$. The mixture was stirred at ambient temperature for 18 hours and then acidified with aqueous hydrochloric acid $(10 \%, 10 \mathrm{~mL})$. The resulting mixture was extracted with ethyl acetate $(3 \times 15 \mathrm{~mL})$. The organic layers were combined, dried over $\mathrm{Na}_{2} \mathrm{SO}_{4}$ and the solvents were evaporated in vacuo. Purification was performed by preparative HPLC to afford the title compound as a yellow solid (5 mg, 12\%). $R_{f}$ (hexane/EtOAc $=4: 1+2 \%$ $\mathrm{AcH})=0.52 .{ }^{1} \mathrm{H}-\mathrm{NMR}\left(500 \mathrm{MHz}, \mathrm{MeOD}-d_{4}\right): \delta=7.54-7.49(\mathrm{~m}, 4 \mathrm{H}), 3.08(\mathrm{t}, J=7.2 \mathrm{~Hz}, 2 \mathrm{H}), 2.82$ (t, $J=7.2 \mathrm{~Hz}, 2 \mathrm{H}), 2.35$ (s, 3H), 1.35 (s, 9H) ppm. ${ }^{13} \mathrm{C}-\mathrm{NMR}\left(126 \mathrm{MHz}, \mathrm{MeOD}-d_{4}\right): \delta=175.66$, $163.21,152.14,146.95,131.60,127.32,126.81,126.18,35.52,31.63,24.34,12.82$ ppm. HRMS (MALDI): $\mathrm{m} / z$ calculated 288.15942 for $\mathrm{C}_{17} \mathrm{H}_{22} \mathrm{NO}_{3}$, found $288.15960\left([\mathrm{M}+\mathrm{H}]^{+}\right)$.

3-[5-(4-tert-Butylphenyl)-1,3,4-oxadiazol-2-yl]propanoic acid (22): Diacylhydrazine 70 (0.25 g, $0.86 \mathrm{mmol}, 1.0 \mathrm{eq}$ ) was dissolved in $4 \mathrm{~mL}$ concentrated sulfuric acid and heated to $80^{\circ} \mathrm{C}$ for 2 hours. The resulting mixture was poured into iced water and the resulting precipitate was filtered off. The solvents of the filtrate were evaporated in vacuo. The crude product was purified by column chromatography in hexane/EtOAc $(2: 1+2 \% \mathrm{AcH})$ to afford the title compound as a yellow oil $(12 \mathrm{mg}, 5 \%) \cdot \mathrm{R}_{\mathrm{f}}($ hexane/EtOAc $=2: 1+2 \% \mathrm{AcH})=0.28 .{ }^{1} \mathrm{H}-\mathrm{NMR}\left(500 \mathrm{MHz}, \mathrm{MeOD}-d_{4}\right): \delta=$ 7.96-7.94 (m, 2H), 7.61-7.59 (m, 2H), $3.22(\mathrm{t}, J=7.2 \mathrm{~Hz}, 2 \mathrm{H}), 2.86(\mathrm{t}, J=7.2 \mathrm{~Hz}, 2 \mathrm{H}), 1.36(\mathrm{~s}, 9 \mathrm{H})$ ppm. ${ }^{13} \mathrm{C}-N M R\left(126 \mathrm{MHz}, \mathrm{MeOD}-d_{4}\right): \delta=176.03,168.04,166.38,156.95,127.68,127.34,122.05$, 
35.96, 31.81, 31.46, 22.19 ppm. HRMS (MALDI): $\mathrm{m} / z$ calculated 275.13902 for $\mathrm{C}_{15} \mathrm{H}_{19} \mathrm{~N}_{2} \mathrm{O}_{3}$, found $275.13941\left([\mathrm{M}+\mathrm{H}]^{+}\right)$.

3-[5-(4-tert-Butylphenyl)-1-methyl-1 H-pyrazol-3-yl]propanoic acid (23): Diketone 72 (0.10 g, $0.36 \mathrm{mmol}, 1.0 \mathrm{eq}$ ) was dissolved in $11 \mathrm{~mL}$ glacial acetic acid and methylhydrazine $(17 \mathrm{mg}, 0.36$ $\mathrm{mmol}, 1.0 \mathrm{eq})$ and sodium acetate $(0.15 \mathrm{~g}, 1.8 \mathrm{mmol}, 5.0 \mathrm{eq})$ were added. The mixture was heated to $80^{\circ} \mathrm{C}$ for 2 hours. After cooling to room temperature the solvent was evaporated in vacuo. The residue was redissolved in an aqueous sodium hydroxide solution $(2 \mathrm{M}, 20 \mathrm{~mL})$, ethyl acetate (30 $\mathrm{mL}$ ) was added, phases were separated, and the organic layer was washed with an aqueous sodium hydroxide solution ( $2 \mathrm{M}, 3 \times 20 \mathrm{~mL}$ ). The combined basic aqueous layers were acidified with aqueous hydrochloric acid $(10 \%, 60 \mathrm{~mL})$ and extracted with ethyl acetate $(4 \times 50 \mathrm{~mL})$. The latter organic layers were combined, dried over $\mathrm{Na}_{2} \mathrm{SO}_{4}$ and the solvents were evaporated in vacuo. Purification was performed by preparative HPLC to afford the title compound as a yellow solid $(11 \mathrm{mg}, 11 \%) . \mathrm{R}_{\mathrm{f}}\left(\mathrm{CH}_{2} \mathrm{Cl}_{2} /\right.$ acetone $=19: 1+2 \%$ acetic acid $)=0.48 .{ }^{1} \mathrm{H}-\mathrm{NMR}(500 \mathrm{MHz}$, MeOD- $\left.d_{4}\right): \delta=7.53-7.50(\mathrm{~m}, 2 \mathrm{H}), 7.39-7.37(\mathrm{~m}, 2 \mathrm{H}), 6.17(\mathrm{~s}, 1 \mathrm{H}), 3.79(\mathrm{~s}, 3 \mathrm{H}), 2.90(\mathrm{t}, J=7.6 \mathrm{~Hz}$, $2 \mathrm{H}$ ), $2.66(\mathrm{t}, J=7.6 \mathrm{~Hz}, 2 \mathrm{H}), 1.35(\mathrm{~s}, 9 \mathrm{H}) \mathrm{ppm} .{ }^{13} \mathrm{C}-\mathrm{NMR}\left(126 \mathrm{MHz}, \mathrm{MeOD}-d_{4}\right): \delta=176.55,153.03$, 152.00, 146.26, 129.50, 128.87, 126.76, 105.46, 37.26, 35.56, 34.84, 31.65, 24.39 ppm. HRMS (MALDI): $\mathrm{m} / \mathrm{z}$ calculated 287.17540 for $\mathrm{C}_{17} \mathrm{H}_{23} \mathrm{~N}_{2} \mathrm{O}_{2}$, found $287.17511\left([\mathrm{M}+\mathrm{H}]^{+}\right)$.

3-[5-(4-tert-Butylphenyl)-1 H-pyrazol-3-yl]propanoic acid (24): Diketone 72 (69 mg, $0.25 \mathrm{mmol}$, $1.0 \mathrm{eq})$ and sodium acetate $(0.11 \mathrm{mg}, 1.3 \mathrm{mmol}, 5.0 \mathrm{eq})$ were dissolved in $10 \mathrm{~mL}$ glacial acetic acid and hydrazine $(1.0 \mathrm{M}$ in ethanol, $0.25 \mathrm{~mL}, 0.25 \mathrm{mmol}, 1.0 \mathrm{eq})$ was added dropwise. The mixture was heated to $80{ }^{\circ} \mathrm{C}$ for 2 hours. After cooling to room temperature the solvent was evaporated in vacuo. The residue was redissolved in an aqueous sodium hydroxide solution ( $2 \mathrm{M}$, $10 \mathrm{~mL}$ ), ethyl acetate $(10 \mathrm{~mL})$ was added, phases were separated and the organic layer was washed with an aqueous sodium hydroxide solution $(2 \mathrm{M}, 3 \times 10 \mathrm{~mL})$. The combined basic aqueous layers were acidified with aqueous hydrochloric acid $(10 \%, 40 \mathrm{~mL})$ and extracted with ethyl acetate $(4 \times 50 \mathrm{~mL})$. The latter organic layers were combined, dried over $\mathrm{Na}_{2} \mathrm{SO}_{4}$ and the solvents were evaporated in vacuo. The crude product was purified by column chromatography in hexane/EtOAc (2:1 + 2\% acetic acid) to afford the title compound as a yellow solid (58 $\mathrm{mg}, 85 \%)$. $\mathrm{R}_{\mathrm{f}}($ hexane/EtOAc $=2: 1+2 \%$ acetic acid $)=0.38 .{ }^{1} \mathrm{H}-\mathrm{NMR}\left(500 \mathrm{MHz}, \mathrm{MeOD}-d_{4}\right): \delta=7.64-7.61$ (m, 2H), 7.45-7.42 (m, 2H), $6.43(\mathrm{~s}, 1 \mathrm{H}), 2.96(\mathrm{t}, J=7.6 \mathrm{~Hz}, 2 \mathrm{H}), 2.69$ (t, $J=7.6 \mathrm{~Hz}, 2 \mathrm{H}), 1.34$ (s, 9H) ppm. ${ }^{13} \mathrm{C}-N M R\left(126 \mathrm{MHz}, \mathrm{MeOD}-d_{4}\right): \delta=176.35,152.21,149.69,149.24,130.28,126.67$, 126.37, 101.77, 35.45, 34.64, 31.69, $23.12 \mathrm{ppm}$. HRMS (MALDI): $\mathrm{m} / \mathrm{z}$ calculated 273.15975 for $\mathrm{C}_{16} \mathrm{H}_{21} \mathrm{~N}_{2} \mathrm{O}_{2}$, found $273.15961\left([\mathrm{M}+\mathrm{H}]^{+}\right)$.

3-[4-(4-tert-Butylphenyl)-1H-1,2,3-triazol-1-yl]propanoic acid (25): A solution of lithium hydroxide monohydrate $(25 \mathrm{mg}, 0.60 \mathrm{mmol}, 3.0 \mathrm{eq})$ in $3 \mathrm{~mL}$ water was added to a solution of the ester 78 ( $59 \mathrm{mg}, 0.20 \mathrm{mmol}, 1.0 \mathrm{eq}$ ) in $5 \mathrm{~mL} \mathrm{EtOH}$. The mixture was stirred at ambient temperature for 20 minutes and then acidified with aqueous hydrochloric acid $(10 \%, 10 \mathrm{~mL})$. The mixture was 
extracted with ethyl acetate $(4 \times 20 \mathrm{~mL})$, the organic layers were combined, dried over $\mathrm{Na}_{2} \mathrm{SO}_{4}$ and the solvents were evaporated in vacuo to afford the product as a white solid (57 mg, quant.). $\mathrm{R}_{\mathrm{f}}\left(\mathrm{CH}_{2} \mathrm{Cl}_{2} / \mathrm{MeOH}=95: 5\right)=0.13 .{ }^{1} \mathrm{H}-\mathrm{NMR}\left(500 \mathrm{MHz}, \mathrm{MeOD}-d_{4}\right): \delta=8.26(\mathrm{~s}, 1 \mathrm{H}), 7.75-7.69(\mathrm{~m}$, $2 \mathrm{H}), 7.50-7.44(\mathrm{~m}, 2 \mathrm{H}), 4.70(\mathrm{t}, J=6.6 \mathrm{~Hz}, 2 \mathrm{H}), 3.02(\mathrm{t}, J=6.6 \mathrm{~Hz}, 2 \mathrm{H}), 1.34(\mathrm{~s}, 9 \mathrm{H}) \mathrm{ppm} .{ }^{13} \mathrm{C}-$ NMR (126 MHz, MeOD- $\left.d_{4}\right): \delta=173.84,152.60,148.71,128.83,126.86,126.45,122.44,47.16$, 35.49, 35.10, 31.68 ppm. HRMS (MALDI): $\mathrm{m} / \mathrm{z}$ calculated 274.15500 for $\mathrm{C}_{15} \mathrm{H}_{20} \mathrm{~N}_{3} \mathrm{O}_{2}$, found $274.15552\left([\mathrm{M}+\mathrm{H}]^{+}\right)$.

(E)-3-[5-(4-tert-Butylphenyl)-1H-pyrazol-3-yl]acrylic acid (26): Diketone 74 (0.12 g, 0.44 mmol, $1.0 \mathrm{eq})$ and sodium acetate $(0.18 \mathrm{mg}, 2.2 \mathrm{mmol}, 5.0 \mathrm{eq})$ were dissolved in $15 \mathrm{~mL}$ glacial acetic acid and hydrazine $(1.0 \mathrm{M}$ in ethanol, $0.44 \mathrm{~mL}, 0.44 \mathrm{mmol}, 1.0 \mathrm{eq}$ ) was added dropwise. The mixture was heated to $80{ }^{\circ} \mathrm{C}$ for 4 hours. After cooling to room temperature the solvent was evaporated in vacuo. The residue was redissolved in an aqueous sodium hydroxide solution ( $2 \mathrm{M}$, $15 \mathrm{~mL}$ ), ethyl acetate $(15 \mathrm{~mL})$ was added, phases were separated, and the organic layer was washed with an aqueous sodium hydroxide solution (2 M, $3 \times 15 \mathrm{~mL}$ ). The combined basic aqueous layers were acidified with aqueous hydrochloric acid $(10 \%, 50 \mathrm{~mL})$ and extracted with ethyl acetate $(4 \times 50 \mathrm{~mL})$. The latter organic layers were combined, dried over $\mathrm{Na}_{2} \mathrm{SO}_{4}$ and the solvents were evaporated in vacuo. Purification was performed by preparative HPLC to afford the title compound as a white solid (10 mg, 8\%). $\mathrm{R}_{\mathrm{f}}\left(\mathrm{CH}_{2} \mathrm{Cl}_{2} / \mathrm{EtOAc}=9: 1+2 \%\right.$ acetic acid $)=0.28$. ${ }^{1} \mathrm{H}-$ $\operatorname{NMR}\left(500 \mathrm{MHz}, \mathrm{MeOD}-d_{4}\right): \delta=7.70-7.64(\mathrm{~m}, 2 \mathrm{H}), 7.61(\mathrm{~d}, J=16.1 \mathrm{~Hz}, 1 \mathrm{H}), 7.50-7.45(\mathrm{~m}, 2 \mathrm{H})$, $6.95(\mathrm{~s}, 1 \mathrm{H}), 6.50(\mathrm{~d}, J=16.0 \mathrm{~Hz}, 1 \mathrm{H}), 1.34(\mathrm{~s}, 9 \mathrm{H}) \mathrm{ppm} .{ }^{13} \mathrm{C}-\mathrm{NMR}\left(126 \mathrm{MHz}, \mathrm{MeOD}-d_{4}\right): \delta=$ 170.16, 152.88, 148.94, 147.31, 135.89, 128.84, 126.89, 126.46, 120.93, 102.81, 35.52, 31.65 ppm. HRMS (MALDI): $\mathrm{m} / z$ calculated 271.14410 for $\mathrm{C}_{16} \mathrm{H}_{19} \mathrm{~N}_{2} \mathrm{O}_{2}$, found $271.14429\left([\mathrm{M}+\mathrm{H}]^{+}\right)$.

2,5-Dimethyl-1-(2-methylphenyl)-1H-pyrrole (40): Preparation according to general procedure A using 2,5-hexanedione $(39,0.44 \mathrm{~g}, 3.9 \mathrm{mmol}, 1.0 \mathrm{eq}), 2$-methylaniline $(27,0.50 \mathrm{~g}, 4.7 \mathrm{mmol}$, $1.2 \mathrm{eq}$ ) and $p$-toluenesulfonic acid monohydrate $(74 \mathrm{mg}, 0.39 \mathrm{mmol}, 0.10 \mathrm{eq})$. Further purification was performed by column chromatography with hexane/EtOAc (4:1) as mobile phase to obtain 40 as a brown solid $(0.72 \mathrm{~g}, 62 \%) . \mathrm{R}_{\mathrm{f}}$ (hexane/EtOAc $\left.=4: 1\right)=0.73 .{ }^{1} \mathrm{H}-\mathrm{NMR}\left(250 \mathrm{MHz}\right.$, DMSO- $\left.d_{6}\right): \delta$ $=7.41-7.30(\mathrm{~m}, 3 \mathrm{H}), 7.18-7.12(\mathrm{~m}, 1 \mathrm{H}), 5.80(\mathrm{~s}, 2 \mathrm{H}), 1.84(\mathrm{~s}, 3 \mathrm{H}), 1.82(\mathrm{~s}, 6 \mathrm{H}) \mathrm{ppm} .{ }^{13} \mathrm{C}-\mathrm{NMR}$ $\left(75 \mathrm{MHz}, \mathrm{DMSO}-d_{6}\right): \delta=137.56,136.43,130.73,128.71,128.54,127.00,126.91,105.46,16.53$, $12.37 \mathrm{ppm}$.

2,5-Dimethyl-1-(3-methylphenyl)-1H-pyrrole (41): Preparation according to general procedure A using 2,5-hexanedione $(39,0.44 \mathrm{~g}, 3.9 \mathrm{mmol}, 1.0 \mathrm{eq})$, 3-methylaniline $(28,0.50 \mathrm{~g}, 4.7 \mathrm{mmol}$, $1.2 \mathrm{eq}$ ) and $p$-toluenesulfonic acid monohydrate ( $74 \mathrm{mg}, 0.39 \mathrm{mmol}, 0.10 \mathrm{eq})$. Further purification was performed by column chromatography with hexane/EtOAc (4:1) as mobile phase to obtain 41 as a brown oil $(0.68 \mathrm{~g}, 94 \%) . \mathrm{R}_{\mathrm{f}}($ hexane/EtOAc $=4: 1)=0.82 .{ }^{1} \mathrm{H}-\mathrm{NMR}\left(250 \mathrm{MHz}, \mathrm{DMSO}-d_{6}\right): \delta=$ $7.38(\mathrm{t}, J=7.6 \mathrm{~Hz}, 1 \mathrm{H}), 7.24(\mathrm{~d}, J=7.6 \mathrm{~Hz}, 1 \mathrm{H}), 7.09-6.98(\mathrm{~m}, 2 \mathrm{H}), 5.77(\mathrm{~s}, 2 \mathrm{H}), 2.36(\mathrm{~s}, 3 \mathrm{H}), 1.95$ 
(s, 6H) ppm. ${ }^{13} \mathrm{C}-\mathrm{NMR}\left(75 \mathrm{MHz}\right.$, DMSO- $\left.d_{6}\right): \delta=138.81,138.29,128.99,128.47,128.31,127.45$, 124.97, 105.76, 20.77, $12.86 \mathrm{ppm}$.

2,5-Dimethyl-1-(4-methylphenyl)-1H-pyrrole (42): Preparation according to general procedure A using 2,5-hexanedione $(39,0.44 \mathrm{~g}, 3.9 \mathrm{mmol}, 1.0 \mathrm{eq})$, 4-methylaniline $(29,0.50 \mathrm{~g}, 4.7 \mathrm{mmol}$, $1.2 \mathrm{eq})$ and $p$-toluenesulfonic acid monohydrate $(74 \mathrm{mg}, 0.39 \mathrm{mmol}, 0.10 \mathrm{eq})$. Further purification was performed by column chromatography with hexane/EtOAc (4:1) as mobile phase to obtain $\mathbf{4 2}$ as a brown oil $(0.69 \mathrm{~g}, 95 \%)$. $R_{\mathrm{f}}($ hexane/EtOAc $=4: 1)=0.22 .{ }^{1} \mathrm{H}-\mathrm{NMR}\left(250 \mathrm{MHz}\right.$, DMSO- $\left.d_{6}\right): \delta=$ 7.33-7.27 (m, 2H), 7.15-7.08 (m, 2H), $5.77(\mathrm{~s}, 2 \mathrm{H}), 2.37$ (s, 3H), $1.93(\mathrm{~s}, 6 \mathrm{H})$ ppm. ${ }^{13} \mathrm{C}-\mathrm{NMR}$ $\left(75 \mathrm{MHz}, \mathrm{DMSO}-d_{6}\right): \delta=137.04,135.78,129.76,127.74,127.52,105.69,20.63,12.85 \mathrm{ppm}$.

1-(4-Methoxyphenyl)-2,5-dimethyl-1 H-pyrrole (43): Preparation according to general procedure A using 2,5-hexanedione $(39,0.20 \mathrm{~g}, 1.8 \mathrm{mmol}, 1.0 \mathrm{eq})$, 4-methoxyaniline $(\mathbf{3 0}, 0.27 \mathrm{~g}, 2.2 \mathrm{mmol}$, $1.2 \mathrm{eq}$ ) and $p$-toluenesulfonic acid monohydrate $(34 \mathrm{mg}, 0.18 \mathrm{mmol}, 0.10 \mathrm{eq})$. Further purification was performed by column chromatography with hexane/EtOAc (95:5) as mobile phase to obtain 43 as an orange solid $(0.31 \mathrm{~g}, 83 \%)$. $\mathrm{R}_{\mathrm{f}}($ hexane/EtOAc $=95: 5)=0.75 .{ }^{1} \mathrm{H}-\mathrm{NMR}\left(250 \mathrm{MHz}, \mathrm{CDCl}_{3}\right)$ : $\delta=7.17-7.09(\mathrm{~m}, 2 \mathrm{H}), 7.01-6.93(\mathrm{~m}, 2 \mathrm{H}), 5.88(\mathrm{~s}, 2 \mathrm{H}), 3.86(\mathrm{~s}, 3 \mathrm{H}), 2.02(\mathrm{~s}, 6 \mathrm{H}) \mathrm{ppm} .{ }^{13} \mathrm{C}-\mathrm{NMR}$ $\left(75 \mathrm{MHz}, \mathrm{CDCl}_{3}\right): \delta=159.02,131.92,129.37,129.18,114.34,105.40,55.60,13.08 \mathrm{ppm}$.

1-(4-Trifluoromethylphenyl)-2,5-dimethyl-1 $H$-pyrrole (44): Preparation according to general procedure A using 2,5-hexanedione $(39,0.11 \mathrm{~g}, 0.96 \mathrm{mmol}, 1.0 \mathrm{eq})$, 4-trifluoromethylaniline (31, $0.19 \mathrm{~g}, 1.2 \mathrm{mmol}, 1.2 \mathrm{eq}$ ) and $p$-toluenesulfonic acid monohydrate (19 mg, $0.10 \mathrm{mmol}, 0.10 \mathrm{eq}$ ). Further purification was performed by column chromatography with hexane/EtOAc (95:5) as mobile phase to obtain 44 as a yellow solid $(0.115 \mathrm{~g}, 51 \%) . \mathrm{R}_{\mathrm{f}}$ (hexane/EtOAc $\left.=95: 5\right)=0.22$. ${ }^{1} \mathrm{H}-\mathrm{NMR}\left(250 \mathrm{MHz}\right.$, DMSO- $\left.d_{6}\right): \delta=7.91-7.84(\mathrm{~m}, 2 \mathrm{H}), 7.58 .7 .47(\mathrm{~m}, 2 \mathrm{H}), 5.85(\mathrm{~s}, 2 \mathrm{H}), 1.99(\mathrm{~s}$, $6 \mathrm{H}) \mathrm{ppm}$.

1-(4-Trifluoromethoxyphenyl)-2,5-dimethyl-1 $H$-pyrrole (45): Preparation according to general procedure A using 2,5-hexanedione (39, $0.27 \mathrm{~g}, 2.4 \mathrm{mmol}, 1.0 \mathrm{eq})$, 4-trifluoromethoxyaniline (32, $0.51 \mathrm{~g}, 2.9 \mathrm{mmol}, 1.2 \mathrm{eq}$ ) and p-toluenesulfonic acid monohydrate (46 mg, $0.24 \mathrm{mmol}, 0.10 \mathrm{eq}$ ). Further purification was performed by column chromatography with hexane/EtOAc (95:5) as mobile phase to obtain 45 as an orange oil $(0.43 \mathrm{~g}, 73 \%)$. $R_{f}($ hexane/EtOAc $=95: 5)=0.76$. ${ }^{1} \mathrm{H}-\mathrm{NMR}\left(250 \mathrm{MHz}\right.$, DMSO- $\left.d_{6}\right): \delta=7.53-7.46(\mathrm{~m}, 2 \mathrm{H}), 7.46-7.37(\mathrm{~m}, 2 \mathrm{H}), 5.81(\mathrm{~s}, 2 \mathrm{H}), 1.96(\mathrm{~s}$, $6 \mathrm{H})$ ppm. ${ }^{13} \mathrm{C}-\mathrm{NMR}\left(75 \mathrm{MHz}\right.$, DMSO- $\left.d_{6}\right): \delta=147.33$ (q, $\left.J=1.8 \mathrm{~Hz}\right), 137.35,129.96,127.64$, $121.75,118.36,106.23,12.77 \mathrm{ppm}$.

1-(4-Chlorophenyl)-2,5-dimethyl-1 H-pyrrole (46): 4-Chloroaniline (33, $0.38 \mathrm{~g}, 3.0 \mathrm{mmol}, 1.0 \mathrm{eq})$ was dissolved in $2 \mathrm{~mL}$ glacial acetic acid and 2,5-hexanedione $(39,1.71 \mathrm{~g}, 15.0 \mathrm{mmol}, 5.00 \mathrm{eq})$ was added. The mixture was stirred at $100^{\circ} \mathrm{C}$ for $60 \mathrm{~min}$. Afterwards the reaction cooled to room temperature and the solvent was removed in vacuo. Further purification was performed by column 
chromatography with hexane/EtOAc (95:5) as mobile phase to obtain $\mathbf{4 6}$ as a yellow solid (0.33 $\mathrm{g}$, $53 \%) . R_{f}($ hexane/EtOAc $=95: 5)=0.90 .{ }^{1} \mathrm{H}-\mathrm{NMR}\left(250 \mathrm{MHz}, \mathrm{DMSO}-d_{6}\right): \delta=7.59-7.53(\mathrm{~m}, 2 \mathrm{H})$, 7.33-7.27 (m, 2H), $5.80(\mathrm{~s}, 2 \mathrm{H}), 1.96(\mathrm{~s}, 6 \mathrm{H})$ ppm. ${ }^{13} \mathrm{C}-\mathrm{NMR}\left(75 \mathrm{MHz}, \mathrm{DMSO}-d_{6}\right): \delta=137.20$, $132.20,129.81,129.25,127.57,106.18,12.77$ ppm.

1-(4-Dimethylaminophenyl)-2,5-dimethyl-1 H-pyrrole (47): Preparation according to general procedure A using 2,5-hexanedione $(39,0.24 \mathrm{~g}, 2.1 \mathrm{mmol}, 1.0 \mathrm{eq}), \quad N, N$-dimethyl- $p$ phenylendiamine $(34,0.34 \mathrm{~g}, 2.5 \mathrm{mmol}, 1.2 \mathrm{eq})$ and $p$-toluenesulfonic acid monohydrate (40 $\mathrm{mg}$, $0.21 \mathrm{mmol}, 0.10 \mathrm{eq})$. Further purification was performed by column chromatography with hexane/EtOAc (95:5) as mobile phase to obtain 47 as a yellow solid $(0.36 \mathrm{~g}, 66 \%)$. $R_{f}$ (hexane/EtOAc = 95:5) = 0.53. ${ }^{1} \mathrm{H}-\mathrm{NMR}\left(250 \mathrm{MHz}\right.$, DMSO- $\left.d_{6}\right): \delta=7.05-6.99(\mathrm{~m}, 2 \mathrm{H}), 6.81-6.75$ $(\mathrm{m}, 2 \mathrm{H}), 5.72(\mathrm{~s}, 2 \mathrm{H}), 2.95(\mathrm{~s}, 6 \mathrm{H}), 1.92(\mathrm{~s}, 6 \mathrm{H}) \mathrm{ppm} .{ }^{13} \mathrm{C}-\mathrm{NMR}$ (75 MHz, DMSO- $\left.d_{6}\right): \delta$ = 149.50, 128.36, 127.73, 126.83, 112.28, 105.09, 40.08, 12.85 ppm.

2,5-Dimethyl-1-(4-(4-morpholinyl)phenyl)-1H-pyrrole (48): Preparation according to general procedure A using 2,5-hexanedione $(39,0.16 \mathrm{~g}, 1.4 \mathrm{mmol}, 1.0 \mathrm{eq})$, 4-morpholinoaniline (35, $0.30 \mathrm{~g}, 1.7 \mathrm{mmol}, 1.2 \mathrm{eq}$ ) and p-toluenesulfonic acid monohydrate (27 mg, $0.14 \mathrm{mmol}, 0.10 \mathrm{eq}$ ). Further purification was performed by column chromatography with $\mathrm{CH}_{2} \mathrm{Cl}_{2} / \mathrm{MeOH}$ (98:2) as mobile phase to obtain 48 as a brown solid (0.135 g, 37\%). $\mathrm{R}_{\mathrm{f}}\left(\mathrm{CH}_{2} \mathrm{Cl}_{2} / \mathrm{MeOH}=98: 2\right)=0.88$. ${ }^{1} \mathrm{H}-\mathrm{NMR}\left(250 \mathrm{MHz}\right.$, DMSO- $\left.d_{6}\right): \delta=7.11-6.98(\mathrm{~m}, 4 \mathrm{H}), 5.74(\mathrm{~s}, 2 \mathrm{H}), 3.79-3.72(\mathrm{~m}, 4 \mathrm{H}), 3.21-3.13$ $(\mathrm{m}, 4 \mathrm{H}), 1.93$ (s, 6H) ppm. ${ }^{13} \mathrm{C}-\mathrm{NMR}$ (75 MHz, DMSO- $\left.d_{6}\right): \delta=150.09,129.45,128.43,127.66$, 115.03, 105.31, 66.10, 48.00, 12.85 ppm.

2,5-Dimethyl-1-(4-phenoxyphenyl)-1H-pyrrole (49): Preparation according to general procedure A using 2,5-hexanedione $(39,0.19 \mathrm{~g}, 1.7 \mathrm{mmol}, 1.0 \mathrm{eq})$, 4-phenoxyaniline $(36,0.37 \mathrm{~g}$, $2.0 \mathrm{mmol}, 1.2 \mathrm{eq}$ ) and p-toluenesulfonic acid monohydrate (32 mg, $0.17 \mathrm{mmol}, 0.10 \mathrm{eq}$ ). Further purification was performed by column chromatography with hexane/EtOAc (95:5) as mobile phase to obtain 49 as a brown solid $(0.47 \mathrm{~g}, 90 \%) . \mathrm{R}_{\mathrm{f}}$ (hexane/EtOAc $\left.=95: 5\right)=0.98 .{ }^{1} \mathrm{H}-\mathrm{NMR}(250 \mathrm{MHz}$, DMSO- $\left.d_{6}\right): \delta=7.49-7.40(\mathrm{~m}, 2 \mathrm{H}), 7.29-7.04(\mathrm{~m}, 7 \mathrm{H}), 5.78(\mathrm{~s}, 2 \mathrm{H}), 1.96(\mathrm{~s}, 6 \mathrm{H}) \mathrm{ppm}$.

2,5-Dimethyl-1-(naphthalene-2-yl)-1H-pyrrole (50): Preparation according to general procedure A using 2,5-hexanedione (39, $0.18 \mathrm{~g}, 1.6 \mathrm{mmol}, 1.0 \mathrm{eq})$, 2-naphthylamine $(37,0.27 \mathrm{~g}, 1.9 \mathrm{mmol}$, $1.2 \mathrm{eq}$ ) and $p$-toluenesulfonic acid monohydrate (30 mg, $0.16 \mathrm{mmol}, 0.10 \mathrm{eq})$. Further purification was performed by column chromatography with hexane/EtOAc (95:5) as mobile phase to obtain 50 as an orange oil $(0.13 \mathrm{~g}, 32 \%) . \mathrm{R}_{\mathrm{f}}$ (hexane/EtOAc $\left.=95: 5\right)=0.64 .{ }^{1} \mathrm{H}-\mathrm{NMR}(300 \mathrm{MHz}$, DMSO- $\left.d_{6}\right): \delta=8.07-7.97(\mathrm{~m}, 3 \mathrm{H}), 7.85(\mathrm{~d}, J=1.9 \mathrm{~Hz}, 1 \mathrm{H}), 7.63-7.55(\mathrm{~m}, 2 \mathrm{H}), 7.38(\mathrm{dd}, J=8.6$, $2.1 \mathrm{~Hz}, 1 \mathrm{H}), 5.84(\mathrm{~s}, 2 \mathrm{H}), 2.00(\mathrm{~s}, 6 \mathrm{H}) \mathrm{ppm} .{ }^{13} \mathrm{C}-\mathrm{NMR}\left(75 \mathrm{MHz}, \mathrm{DMSO}-d_{6}\right): \delta=135.81,133.08$, 131.93, 128.94, 127.93, 127.76, 127.66, 126.73, 126.58, 126.26, 126.25, 106.02, 12.93 ppm. 
1-(1-(4-tert-Butyl)phenyl)-4-yl-2,5-dimethyl-1H-pyrrole (51): Preparation according to general procedure A using 2,5-hexanedione $(39,1.59 \mathrm{~g}, 13.9 \mathrm{mmol}, 1.00 \mathrm{eq})$, tert-butylaniline $(38,2.49 \mathrm{~g}$, $16.7 \mathrm{mmol}, 1.20 \mathrm{eq}$ ) and $p$-toluenesulfonic acid monohydrate (27 mg, $0.14 \mathrm{mmol}, 0.10 \mathrm{eq})$. Further purification was performed by column chromatography with hexane/EtOAc $(5: 1)$ as mobile phase to obtain 51 as a yellow solid $(3.08 \mathrm{~g}, 97 \%) . R_{\mathrm{f}}$ (hexane/EtOAc $\left.=5: 1\right)=0.89 .{ }^{1} \mathrm{H}-\mathrm{NMR}(400$ MHz, DMSO- $\left.d_{6}\right): \delta=7.53-7.49(\mathrm{~m}, 2 \mathrm{H}), 7.17-7.14(\mathrm{~m}, 2 \mathrm{H}), 5.76(\mathrm{~s}, 2 \mathrm{H}), 1.94(\mathrm{~s}, 6 \mathrm{H}), 1.32(\mathrm{~s}, 9 \mathrm{H})$ ppm. ${ }^{13} \mathrm{C}-\mathrm{NMR}\left(101 \mathrm{MHz}\right.$, DMSO- $\left.d_{6}\right): \delta=150.02,135.80,127.63,127.52,126.03,105.80,34.45$, 31.19, $12.99 \mathrm{ppm}$.

2,5-Dimethyl-1-(2-methylphenyl)-1H-pyrrole-3-carbaldehyde (52): Preparation according to general procedure B using 2,5-dimethyl-1-(2-methylphenyl)-1H-pyrrole $(\mathbf{4 0}, 0.72 \mathrm{~g}, 3.9 \mathrm{mmol}$, $1.0 \mathrm{eq})$ and phosphoryl chloride $(0.98 \mathrm{~mL}, 11 \mathrm{mmol}, 2.7 \mathrm{eq})$. Further purification was performed by column chromatography with hexane/EtOAc (4:1) as mobile phase to obtain $\mathbf{5 2}$ as a brown oil $(247 \mathrm{mg}, 30 \%) . \mathrm{R}_{\mathrm{f}}$ (hexane/EtOAc $\left.=4: 1\right)=0.32 .{ }^{1} \mathrm{H}-\mathrm{NMR}\left(250 \mathrm{MHz}, \mathrm{DMSO}-d_{6}\right): \delta=9.80(\mathrm{~s}, 1 \mathrm{H})$, 7.52-7.33 (m, 3H), 7.26-7.22 (m, 1H), $6.31(\mathrm{~s}, 1 \mathrm{H}), 2.12(\mathrm{~s}, 3 \mathrm{H}), 1.90(\mathrm{~s}, 3 \mathrm{H}), 1.83(\mathrm{~s}, 3 \mathrm{H}) \mathrm{ppm}$. ${ }^{13} \mathrm{C}-\mathrm{NMR}\left(75 \mathrm{MHz}\right.$, DMSO- $\left.d_{6}\right): \delta=184.78,135.89,135.51,131.15,130.06,129.52,128.38$, 127.37, 121.52, 105.01, 16.57, 11.96, 10.38 ppm.

2,5-Dimethyl-1-(3-methylphenyl)-1H-pyrrole-3-carbaldehyde (53): Preparation according to general procedure B using 2,5-dimethyl-1-(3-methylphenyl)-1 H-pyrrole (41, $0.68 \mathrm{~g}, 3.7 \mathrm{mmol}$, $1.0 \mathrm{eq})$ and phosphoryl chloride $(0.93 \mathrm{~mL}, 10 \mathrm{mmol}, 2.7 \mathrm{eq})$. Further purification was performed by column chromatography with hexane/EtOAc (4:1) as mobile phase to obtain $\mathbf{5 3}$ as an orange oil $(0.30 \mathrm{~g}, 38 \%)$. $\mathrm{R}_{\mathrm{f}}($ hexane/EtOAc $=4: 1)=0.32 .{ }^{1} \mathrm{H}-\mathrm{NMR}\left(250 \mathrm{MHz}, \mathrm{DMSO}-d_{6}\right): \delta=9.80(\mathrm{~s}, 1 \mathrm{H})$, $7.46(\mathrm{t}, J=7.6 \mathrm{~Hz}, 1 \mathrm{H}), 7.34$ (d, J=7.6 Hz, 1H), 7.20-7.08 (m, 2H), $6.28(\mathrm{~s}, 1 \mathrm{H}), 2.39(\mathrm{~s}, 3 \mathrm{H}), 2.23$ (s, 3H), 1.94 (s, 3H) ppm. ${ }^{13} \mathrm{C}-N M R\left(75 \mathrm{MHz}\right.$, DMSO-d $\left.d_{6}\right): \delta=184.77,139.39,138.67,136.31$, $130.49,129.55,129.41,128.33,124.90,121.45,105.06,20.74,12.40,10.74$ ppm.

2,5-Dimethyl-1-(4-methylphenyl)-1H-pyrrole-3-carbaldehyde (54): Preparation according to general procedure B using 2,5-dimethyl-1-(4-methylphenyl)-1 $\mathrm{H}$-pyrrole $(42,0.69 \mathrm{~g}, 3.7 \mathrm{mmol}$, $1.0 \mathrm{eq})$ and phosphoryl chloride $(0.93 \mathrm{~mL}, 10 \mathrm{mmol}, 2.7 \mathrm{eq})$. Further purification was performed by column chromatography with hexane/EtOAc (4:1) as mobile phase to obtain $\mathbf{5 4}$ as a brown oil $(0.255 \mathrm{~g}, 32 \%) . \mathrm{R}_{\mathrm{f}}$ (hexane/EtOAc $\left.=4: 1\right)=0.50 .{ }^{1} \mathrm{H}-\mathrm{NMR}\left(250 \mathrm{MHz}, \mathrm{DMSO}-d_{6}\right): \delta=9.79(\mathrm{~s}, 1 \mathrm{H})$, 7.37 (d, $J=7.8 \mathrm{~Hz}, 2 \mathrm{H}$ ), 7.22 (d, J = 7.8 Hz, 2H), 6.27 (s, 1H), 2.40 (s, 3H), 2.22 (s, 3H), 1.93 (s, $3 \mathrm{H})$ ppm. ${ }^{13} \mathrm{C}-\mathrm{NMR}\left(75 \mathrm{MHz}\right.$, DMSO- $\left.d_{6}\right): \delta=184.73,138.76,138.45,133.78,130.55,130.12$, 127.66, 121.42, 104.99, 20.68, 12.38, $10.71 \mathrm{ppm}$.

1-(4-Methoxyphenyl)-2,5-dimethyl-1H-pyrrole-3-carbaldehyde (55): Preparation according to general procedure B using 1-(4-methoxyphenyl)-2,5-dimethyl-1H-pyrrole (43, $0.30 \mathrm{~g}, 1.5 \mathrm{mmol}$, $1.0 \mathrm{eq}$ ) and phosphoryl chloride $(0.38 \mathrm{~mL}, 4.1 \mathrm{mmol}, 2.7 \mathrm{eq})$. Further purification was performed by column chromatography with $\mathrm{CH}_{2} \mathrm{Cl}_{2} / \mathrm{MeOH}$ (98:2) as mobile phase to obtain 55 as an orange 
solid (0.29 g, 86\%). $\mathrm{R}_{\mathrm{f}}\left(\mathrm{CH}_{2} \mathrm{Cl}_{2} / \mathrm{MeOH}=98: 2\right)=0.88 .{ }^{1} \mathrm{H}-\mathrm{NMR}\left(250 \mathrm{MHz}, \mathrm{DMSO}-d_{6}\right): \delta=9.79$ (s, $1 \mathrm{H}), 7.31-7.22(\mathrm{~m}, 2 \mathrm{H}), 7.13-7.05(\mathrm{~m}, 2 \mathrm{H}), 6.26(\mathrm{~s}, 1 \mathrm{H}), 3.83(\mathrm{~s}, 3 \mathrm{H}), 2.22(\mathrm{~s}, 3 \mathrm{H}), 1.93(\mathrm{~s}, 3 \mathrm{H})$ ppm. ${ }^{13} \mathrm{C}-\mathrm{NMR}\left(75 \mathrm{MHz}\right.$, DMSO- $\left.d_{6}\right): \delta=184.69,159.23,130.76,129.07,128.93,121.32,114.71$, 104.83, 55.42, 12.36, $10.70 \mathrm{ppm}$.

1-(4-Trifluoromethylphenyl)-2,5-dimethyl-1H-pyrrole-3-carbaldehyde $\quad$ (56): Preparation according to general procedure B using 1-(4-trifluoromethylphenyl)-2,5-dimethyl-1 $\mathrm{H}$-pyrrole (44, $0.15 \mathrm{~g}, 0.63 \mathrm{mmol}, 1.0 \mathrm{eq})$ and phosphoryl chloride $(0.16 \mathrm{~mL}, 1.7 \mathrm{mmol}, 2.7 \mathrm{eq})$. Further purification was performed by column chromatography with $\mathrm{CH}_{2} \mathrm{Cl}_{2} / \mathrm{MeOH}$ (98:2) as mobile phase to obtain 55 as a brown oil $(0.09 \mathrm{~g}, 54 \%)$. $\mathrm{R}_{\mathrm{f}}\left(\mathrm{CH}_{2} \mathrm{Cl}_{2} / \mathrm{MeOH}=98: 2\right)=0.98$. ${ }^{1} \mathrm{H}-\mathrm{NMR}(250 \mathrm{MHz}$, DMSO- $\left.d_{6}\right): \delta=9.83(\mathrm{~s}, 1 \mathrm{H}), 7.96(\mathrm{~d}, J=8.3 \mathrm{~Hz}, 2 \mathrm{H}), 7.64(\mathrm{~d}, J=8.2 \mathrm{~Hz}, 2 \mathrm{H}), 6.33(\mathrm{~s}, 1 \mathrm{H}), 2.26$ (s, 3H), 1.97 (s, 3H) ppm.

1-(4-Trifluoromethoxyphenyl)-2,5-dimethyl-1 H-pyrrole-3-carbaldehyde (57): Preparation according to general procedure B using 1-(4-trifluoromethoxyphenyl)-2,5-dimethyl-1 $\mathrm{H}$-pyrrole (45, $0.43 \mathrm{~g}, 1.7 \mathrm{mmol}, 1.0 \mathrm{eq})$ and phosphoryl chloride $(0.43 \mathrm{~mL}, 4.6 \mathrm{mmol}, 2.7 \mathrm{eq})$. Further purification was performed by column chromatography with $\mathrm{CH}_{2} \mathrm{Cl}_{2} / \mathrm{MeOH}$ (98:2) as mobile phase to obtain 57 as a brown oil $(0.28 \mathrm{~g}, 65 \%) . \mathrm{R}_{\mathrm{f}}\left(\mathrm{CH}_{2} \mathrm{Cl}_{2} / \mathrm{MeOH}=98: 2\right)=0.65$. ${ }^{1} \mathrm{H}-\mathrm{NMR}(250 \mathrm{MHz}$, DMSO- $\left.d_{6}\right): \delta=9.82(\mathrm{~s}, 1 \mathrm{H}), 7.62-7.48(\mathrm{~m}, 4 \mathrm{H}), 6.31(\mathrm{~d}, J=0.9 \mathrm{~Hz}, 1 \mathrm{H}), 2.25(\mathrm{~s}, 3 \mathrm{H}), 1.95(\mathrm{~d}, J=$ $0.9 \mathrm{~Hz}, 3 \mathrm{H})$ ppm. ${ }^{13} \mathrm{C}-\mathrm{NMR}\left(75 \mathrm{MHz}, \mathrm{DMSO}-d_{6}\right): \delta=184.89,148.22$ (q, J = $\left.1.9 \mathrm{~Hz}\right), 138.77$, $135.34,130.57,130.20,122.11,121.68,105.31,12.35,10.70$ ppm.

1-(4-Chlorophenyl)-2,5-dimethyl-1H-pyrrole-3-carbaldehyde (58): Preparation according to general procedure B using 1-(4-chlorophenyl)-2,5-dimethyl-1H-pyrrole (46, $0.33 \mathrm{~g}, 1.6 \mathrm{mmol}$, $1.0 \mathrm{eq})$ and phosphoryl chloride $(0.40 \mathrm{~mL}, 4.3 \mathrm{mmol}, 2.7 \mathrm{eq})$. Further purification was performed by column chromatography with $\mathrm{CH}_{2} \mathrm{Cl}_{2} / \mathrm{MeOH}$ (98:2) as mobile phase to obtain 58 as a brown solid $(0.32 \mathrm{~g}, 85 \%) \cdot \mathrm{R}_{\mathrm{f}}\left(\mathrm{CH}_{2} \mathrm{Cl}_{2} / \mathrm{MeOH}=98: 2\right)=0.98 .{ }^{1} \mathrm{H}-\mathrm{NMR}\left(250 \mathrm{MHz}\right.$, DMSO- $\left.d_{6}\right): \delta=9.81$ (s, $1 \mathrm{H}), 7.70-7.58(\mathrm{~m}, 2 \mathrm{H}), 7.46-7.35(\mathrm{~m}, 2 \mathrm{H}), 6.30(\mathrm{~s}, 1 \mathrm{H}), 2.24(\mathrm{~s}, 3 \mathrm{H}), 1.95(\mathrm{~s}, 3 \mathrm{H}) \mathrm{ppm} .{ }^{13} \mathrm{C}-\mathrm{NMR}$ $\left(75 \mathrm{MHz}\right.$, DMSO- $\left.d_{6}\right): \delta=184.85,138.75,135.24,133.55,130.53,129.91,129.67,121.66,105.27$, 12.33, 10.67 ppm.

1-(4-Dimethylaminophenyl)-2,5-dimethyl-1 H-pyrrole-3-carbaldehyde (59): Preparation according to general procedure B using 1-(4-dimethylaminophenyl)-2,5-dimethyl-1 $\mathrm{H}$-pyrrole (47, $0.36 \mathrm{~g}, 1.7 \mathrm{mmol}, 1.0 \mathrm{eq})$ and phosphoryl chloride $(0.43 \mathrm{~mL}, 4.6 \mathrm{mmol}, 2.7 \mathrm{eq})$. Further purification was performed by column chromatography with $\mathrm{CH}_{2} \mathrm{Cl}_{2} / \mathrm{MeOH}$ (98:2) as mobile phase to obtain 59 as a yellow solid $(0.24 \mathrm{~g}, 59 \%) . \mathrm{R}_{\mathrm{f}}\left(\mathrm{CH}_{2} \mathrm{Cl}_{2} / \mathrm{MeOH}=98: 2\right)=0.64 .{ }^{1} \mathrm{H}-\mathrm{NMR}(300 \mathrm{MHz}$, DMSO- $\left.d_{6}\right): \delta=9.77(\mathrm{~s}, 1 \mathrm{H}), 7.13-7.08(\mathrm{~m}, 2 \mathrm{H}), 6.84-6.79(\mathrm{~m}, 2 \mathrm{H}), 6.24(\mathrm{~d}, J=1.0 \mathrm{~Hz}, 1 \mathrm{H}), 2.97$ (s, 6H), $2.21(\mathrm{~s}, 3 \mathrm{H}), 1.92(\mathrm{~d}, J=0.8 \mathrm{~Hz}, 3 \mathrm{H}) \mathrm{ppm} .{ }^{13} \mathrm{C}-\mathrm{NMR}\left(75 \mathrm{MHz}, \mathrm{DMSO}-d_{6}\right): \delta=184.56$, $150.11,139.21,130.94,128.19,124.48,121.13,112.28,104.59,39.96,12.41,10.74$ ppm. 
2,5-Dimethyl-1-(4-(4-morphonlinyl)phenyl)-1 H-pyrrole-3-carbaldehyde (60): Preparation according to general procedure B using 2,5-dimethyl-1-(4-(4-morpholinyl)phenyl)-1 H-pyrrole (48, $0.14 \mathrm{~g}, 0.55 \mathrm{mmol}, 1.0 \mathrm{eq})$ and phosphoryl chloride $(0.14 \mathrm{~mL}, 1.5 \mathrm{mmol}, 2.7 \mathrm{eq})$. Further purification was performed by column chromatography with $\mathrm{CH}_{2} \mathrm{Cl}_{2} / \mathrm{MeOH}$ (98:2) as mobile phase to obtain 60 as a brown oil $(0.10 \mathrm{~g}, 68 \%)$. $\mathrm{R}_{\mathrm{f}}\left(\mathrm{CH}_{2} \mathrm{Cl}_{2} / \mathrm{MeOH}=98: 2\right)=0.75$. ${ }^{1} \mathrm{H}-\mathrm{NMR}(300 \mathrm{MHz}$, DMSO- $\left.d_{6}\right): \delta=9.78(\mathrm{~s}, 1 \mathrm{H}), 7.22-7.12(\mathrm{~m}, 2 \mathrm{H}), 7.12-7.02(\mathrm{~m}, 2 \mathrm{H}), 6.25(\mathrm{~d}, J=1.0 \mathrm{~Hz}, 1 \mathrm{H}), 3.79-$ $3.72(\mathrm{~m}, 4 \mathrm{H}), 3.20(\mathrm{~d}, J=9.8 \mathrm{~Hz}, 4 \mathrm{H}), 2.22(\mathrm{~s}, 3 \mathrm{H}), 1.93(\mathrm{~d}, J=1.0 \mathrm{~Hz}, 3 \mathrm{H}) \mathrm{ppm}$.

2,5-Dimethyl-1-(4-phenoxyphenyl)-1H-pyrrole-3-carbaldehyde (61): Preparation according to genedral procedure B using 2,5-dimethyl-1-(4-phenoxyphenyl)-1 H-pyrrole (49, $0.25 \mathrm{~g}, 0.95 \mathrm{mmol}$, $1.0 \mathrm{eq})$ and phosphoryl chloride $(0.24 \mathrm{~mL}, 2.6 \mathrm{mmol}, 2.7 \mathrm{eq})$. Further purification was performed by column chromatography with $\mathrm{CH}_{2} \mathrm{Cl}_{2} / \mathrm{MeOH}$ (98:2) as mobile phase to obtain 61 as an orange oil $(0.25 \mathrm{~g}, 90 \%) \cdot \mathrm{R}_{\mathrm{f}}\left(\mathrm{CH}_{2} \mathrm{Cl}_{2} / \mathrm{MeOH}=98: 2\right)=0.95$. ${ }^{1} \mathrm{H}-\mathrm{NMR}\left(250 \mathrm{MHz}, \mathrm{DMSO}-d_{6}\right): \delta=9.80(\mathrm{~s}$, $1 \mathrm{H}), 7.52-7.41(\mathrm{~m}, 2 \mathrm{H}), 7.38-7.32(\mathrm{~m}, 2 \mathrm{H}), 7.26-7.17(\mathrm{~m}, 1 \mathrm{H}), 7.17-7.09(\mathrm{~m}, 4 \mathrm{H}), 6.28(\mathrm{~s}, 1 \mathrm{H}), 2.25$ (s, 3H), 1.96 (s, 3H) ppm. ${ }^{13} \mathrm{C}-\mathrm{NMR}(75 \mathrm{MHz}$, DMSO-d $): \delta=184.75,157.19,155.73,138.92$, 131.16, 130.68, 130.28, 129.65, 124.30, 121.44, 119.51, 118.63, 104.99, 12.39, 10.74 ppm.

2,5-Dimethyl-1-(naphthalene-2-yl)-1H-pyrrole-3-carbaldehyde (62): Preparation according to general procedure B using 2,5-dimethyl-1-(naphthalene-2-yl)-1 $\mathrm{H}$-pyrrole $(\mathbf{5 0}, 0.13 \mathrm{~g}, 0.59 \mathrm{mmol}$, $1.0 \mathrm{eq}$ ) and phosphoryl chloride $(0.15 \mathrm{~mL}, 1.6 \mathrm{mmol}, 2.7 \mathrm{eq})$. Further purification was performed by column chromatography with $\mathrm{CH}_{2} \mathrm{Cl}_{2} / \mathrm{MeOH}$ (98:2) as mobile phase to obtain 62 as an orange solid $(0.12 \mathrm{~g}, 78 \%) . \mathrm{R}_{\mathrm{f}}\left(\mathrm{CH}_{2} \mathrm{Cl}_{2} / \mathrm{MeOH}=98: 2\right)=0.76 .{ }^{1} \mathrm{H}-\mathrm{NMR}\left(250 \mathrm{MHz}, \mathrm{DMSO}-d_{6}\right): \delta=9.84(\mathrm{~s}$, $1 \mathrm{H})$, 8.15-7.93 (m, 4H), 7.69-7.60 (m, 2H), $7.46(\mathrm{dd}, J=8.6,2.1 \mathrm{~Hz}, 1 \mathrm{H}), 6.34(\mathrm{~s}, 1 \mathrm{H}), 2.28(\mathrm{~s}$, $3 \mathrm{H}), 1.99$ (s, 3H) ppm. ${ }^{13} \mathrm{C}-\mathrm{NMR}\left(126 \mathrm{MHz}\right.$, DMSO- $\left.d_{6}\right): \delta=184.82,138.91,133.79,132.95$, $132.44,130.74,129.47,128.11,127.78,127.17,127.04,126.73,125.60,121.60,105.20,12.46$, $10.80 \mathrm{ppm}$.

1-(1-(4-tert-Butyl)phenyl)-4-yl-2,5-dimethyl-1H-pyrrole-3-carbaldehyde (63): Preparation according to general procedure B using 1-(1-(4-tert-butyl)phenyl)-4-yl-2,5-dimethyl-1H-pyrrole (51, $0.24 \mathrm{~g}, 1.1 \mathrm{mmol}, 1.0 \mathrm{eq})$ and phosphoryl chloride $(0.28 \mathrm{~mL}, 3.0 \mathrm{mmol}, 2.7 \mathrm{eq})$. Further purification was performed by column chromatography with hexane/EtOAc (4:1) as mobile phase to obtain 63 as an orange oil $(0.155 \mathrm{~g}, 57 \%)$. $\mathrm{R}_{\mathrm{f}}$ (hexane/EtOAc $\left.=4: 1\right)=0.61 .{ }^{1} \mathrm{H}-\mathrm{NMR}(250 \mathrm{MHz}$, DMSO- $\left.d_{6}\right): \delta=9.79(\mathrm{~s}, 1 \mathrm{H}), 7.62-7.54(\mathrm{~m}, 2 \mathrm{H}), 7.28-7.25(\mathrm{~m}, 2 \mathrm{H}), 6.28(\mathrm{~s}, 1 \mathrm{H}), 2.22(\mathrm{~s}, 3 \mathrm{H}), 1.93$ $(\mathrm{s}, 3 \mathrm{H}), 1.34(\mathrm{~s}, 9 \mathrm{H}) \mathrm{ppm} .{ }^{13} \mathrm{C}-\mathrm{NMR}(126 \mathrm{MHz}$, DMSO-d $): \delta=184.75,151.29,138.78,133.77$, $130.59,127.43,126.37,121.43,105.06,34.52,31.05,12.47,10.81$ ppm.

Methyl 3-[5-(4-tert-butylphenyl)-4-methyloxazol-2-yl]propanoate $\quad$ (67): 4-tertButylpropiophenone $(65,0.20 \mathrm{~g}, 1.1 \mathrm{mmol}, 1.0 \mathrm{eq})$, methyl 3-cyanopropionate $(66,1.2 \mathrm{~mL}, 11$ mmol, $10 \mathrm{eq})$, Oxone $(0.74 \mathrm{~g}, 1.2 \mathrm{mmol}, 1.1 \mathrm{eq})$, iodine $(0.20 \mathrm{~g}, 0.77 \mathrm{mmol}, 0.70 \mathrm{eq})$ and triflic acid $(0.77 \mathrm{~mL}, 8.8 \mathrm{mmol}, 8.0 \mathrm{eq})$ were mixed and heated to $100{ }^{\circ} \mathrm{C}$ for 5 hours. After cooling to 
room temperature the mixture was poured into a 1:1 mixture of saturated aqueous $\mathrm{NaHCO}_{3}$ and $\mathrm{NaHSO}_{3}$ solutions $(50 \mathrm{~mL})$. The mixture was extracted with ethyl acetate $(3 \times 30 \mathrm{~mL})$. The organic layers were combined, dried over $\mathrm{Na}_{2} \mathrm{SO}_{4}$ and the solvents were evaporated in vacuo. The crude product was purified by column chromatography in a gradient of hexane/EtOAc $(20: 1$ to $7: 1)$ to afford the title compound as a yellow oil $(45 \mathrm{mg}, 14 \%) . \mathrm{R}_{\mathrm{f}}$ (hexane/EtOAc $\left.=4: 1\right)=0.25$. ${ }^{1} \mathrm{H}-\mathrm{NMR}$ (500 MHz, DMSO- $\left.d_{6}\right): \delta=7.49(\mathrm{~s}, 4 \mathrm{H}), 3.62(\mathrm{~s}, 3 \mathrm{H}), 3.01(\mathrm{t}, J=7.1 \mathrm{~Hz}, 2 \mathrm{H}), 2.80(\mathrm{t}, J=7.1 \mathrm{~Hz}$, $2 \mathrm{H}$ ), $2.28(\mathrm{~s}, 3 \mathrm{H}), 1.30$ (s, 9H) ppm. ${ }^{13} \mathrm{C}-\mathrm{NMR}\left(126 \mathrm{MHz}, \mathrm{DMSO}-d_{6}\right): \delta=172.17,160.73,150.08$, 144.35, 130.79, 125.84, 125.74, 124.64, 51.52, 34.36, 30.98, 29.99, 22.75, 12.89 ppm.

4-[N'-(4-tert-Butylbenzoyl)hydrazinyl]-4-oxobutanoic acid (70): Succinic anhydride (69, $0.13 \mathrm{~g}, 1.3 \mathrm{mmol}, 1.0 \mathrm{eq})$ was dissolved in $6 \mathrm{~mL} N, N$-dimethylacetamide. Then $N, N-$ diisopropylethylamine $(0.34 \mathrm{~mL}, 2.0 \mathrm{mmol}, 1.5 \mathrm{eq})$ and 4-tert-butylbenzohydrazide $(68,0.25 \mathrm{~g}$, $1.3 \mathrm{mmol}, 1.0 \mathrm{eq}$ ) were added and the mixture was stirred at ambient temperature for 18 hours. The solvents were evaporated in vacuo and the residue was redissolved in acetone and acidified with glacial acetic acid. The crude product was purified by column chromatography in hexane/acetone $(2: 1+2 \% \mathrm{AcH})$ to afford the title compound as a yellow oil (502 mg, quant.). $\mathrm{R}_{f}$ (hexane/acetone $=2: 1+2 \% \mathrm{AcH})=0.42 .{ }^{1} \mathrm{H}-\mathrm{NMR}\left(500 \mathrm{MHz}\right.$, acetone- $\left.d_{6}\right): \delta=9.55(\mathrm{~s}, 1 \mathrm{H}), 7.89$ $7.87(\mathrm{~m}, 2 \mathrm{H}), 7.52-7.51(\mathrm{~m}, 2 \mathrm{H}), 2.65-2.59(\mathrm{~m}, 4 \mathrm{H}), 1.33$ (s, 9H) ppm. ${ }^{13} \mathrm{C}-\mathrm{NMR}(126 \mathrm{MHz}, \mathrm{MeOD}-$ $\left.d_{4}\right): \delta=174.00,171.49,166.38,155.90,130.88,128.16,126.14,37.89,31.36,29.13,21.42$ ppm.

6-(4-tert-Butylphenyl)-4,6-dioxohexanoic acid (72): A solution of lithium bis(trimethylsilyl)amide (1.3 M in THF, $0.65 \mathrm{~mL}, 0.85 \mathrm{mmol}, 1.1 \mathrm{eq}$ ) was added dropwise to $5 \mathrm{~mL} \mathrm{THF}$ at $-20^{\circ} \mathrm{C}$. Then a solution of 4-tert-butylacetophenone $(71,0.15 \mathrm{~g}, 0.85 \mathrm{mmol}, 1.1 \mathrm{eq})$ in $3 \mathrm{~mL}$ THF was added dropwise over a period of 10 minutes. The solution was stirred at $-15^{\circ} \mathrm{C}$ for 30 minutes before a solution of succinic anhydride $(69,77 \mathrm{mg}, 0.77 \mathrm{mmol}, 1.0 \mathrm{eq})$ in $3 \mathrm{~mL}$ THF was added dropwise over a period of 10 minutes. While stirring, the resulting mixture was allowed to warm to room temperature and stirred for 18 hours. The mixture was acidified with aqueous hydrochloric acid $(10 \%, 10 \mathrm{~mL})$, diethylether $(20 \mathrm{~mL})$ was added, phases were separated, and the organic layer was washed with aqueous hydrochloric acid $(10 \%, 3 \times 10 \mathrm{~mL})$. The organic layer was extracted with an aqueous sodium hydroxide solution ( $1 \mathrm{M}, 5 \times 15 \mathrm{~mL}$ ), the combined basic aqueous layers were acidified with aqueous hydrochloric acid $(10 \%, 40 \mathrm{~mL})$ and extracted with $\mathrm{CH}_{2} \mathrm{Cl}_{2}(3 \times 50 \mathrm{~mL})$. The latter organic layers were combined, dried over $\mathrm{Na}_{2} \mathrm{SO}_{4}$ and the solvents were evaporated in vacuo. The crude product was purified by column chromatography in a gradient of hexane/EtOAc ( $4: 1$ to $4: 1+2 \%$ acetic acid) to afford the title compound as an orange solid (69 $\mathrm{mg}, 20 \%)$. $\mathrm{R}_{\mathrm{f}}$ (hexane/EtOAc $=4: 1+2 \%$ acetic acid $)=0.42 .{ }^{1} \mathrm{H}-\mathrm{NMR}\left(500 \mathrm{MHz}, \mathrm{DMSO}-d_{6}\right): \delta=7.88-7.85(\mathrm{~m}$, $2 \mathrm{H}$ ), 7.55-7.53 (m, $2 \mathrm{H}), 6.53\left(\mathrm{~s}, 0.6 \cdot 1 \mathrm{H}_{\text {Enol }}\right), 4.26\left(\mathrm{~s}, 0.4 \cdot 2 \mathrm{H}_{\text {Ketone }}\right), 2.82$ (t, J = $6.5 \mathrm{~Hz}, 0.4 \cdot 2 \mathrm{H}_{\text {Ketone }}$ ), 2.74 (t, $\left.J=6.8 \mathrm{~Hz}, 0.6 \cdot 2 \mathrm{H}_{\text {Enol }}\right), 2.57$ (t, $\left.J=6.8 \mathrm{~Hz}, 0.6 \cdot 2 \mathrm{H}_{\text {Enol }}\right), 2.43$ (t, $J=6.5 \mathrm{~Hz}, 0.4 \cdot 2 \mathrm{H}_{\text {Ketone }}$ ), 1.30 (s, 9H) ppm. ${ }^{13} \mathrm{C}-\mathrm{NMR}\left(126 \mathrm{MHz}\right.$, DMSO- $\left.d_{6}\right): \delta=204.43,198.36,194.53,179.10,173.64,173.55$, $156.70,155.71,133.84,130.90$, 128.53, 126.69, 125.74, 125.57, 96.07, 52.89, 37.67, 34.89, $34.83,34.15,30.84,30.79,28.56,27.65$ ppm. 
6-(4-tert-Butylphenyl)-4,6-dioxohex-2-enoic acid (74): A solution of lithium bis(trimethylsilyl)amide $(1.0 \mathrm{M}$ in hexane, $0.86 \mathrm{~mL}, 0.86 \mathrm{mmol}, 1.1 \mathrm{eq})$ was added dropwise to $5 \mathrm{~mL}$ THF at $-15^{\circ} \mathrm{C}$ before a solution of 4 -tert-butylacetophenone $(71,0.15 \mathrm{~g}, 0.86 \mathrm{mmol}, 1.1 \mathrm{eq})$ in $3 \mathrm{~mL}$ THF was added dropwise over a period of 10 minutes. The solution was stirred at $-15^{\circ} \mathrm{C}$ for 30 minutes and a solution of maleic anhydride $(73,76 \mathrm{mg}, 0.78 \mathrm{mmol}, 1.0 \mathrm{eq})$ in $3 \mathrm{~mL}$ THF was added dropwise over a period of 15 minutes. While stirring, the resulting mixture was allowed to warm to room temperature and stirred for 18 hours. The mixture was acidified with aqueous hydrochloric acid $(10 \%, 20 \mathrm{~mL})$, ethyl acetate $(20 \mathrm{~mL})$ was added, phases were separated, and the organic layer was washed with aqueous hydrochloric acid $(10 \%, 3 \times 20 \mathrm{~mL})$. The organic layer was then extracted with an aqueous sodium hydroxide solution (1 M, $5 \times 20 \mathrm{~mL}$ ), the combined basic aqueous layers were acidified with aqueous hydrochloric acid (10\%, $50 \mathrm{~mL})$ and extracted with ethyl acetate $(3 \times 50 \mathrm{~mL})$. The latter organic layers were combined, dried over $\mathrm{Na}_{2} \mathrm{SO}_{4}$ and the solvents were evaporated in vacuo. The crude product was purified by column chromatography in a gradient of hexane/EtOAc $(6: 1+2 \%$ acetic acid to $4: 1+2 \%$ acetic acid $)$ to afford the title compound as a yellow solid (23 mg, 11\%). $R_{f}$ (hexane/EtOAc $=4: 1+2 \%$ acetic acid) $=0.39 .{ }^{1} \mathrm{H}-\mathrm{NMR}\left(250 \mathrm{MHz}, \mathrm{MeOD}-d_{4}\right): \delta=7.98(\mathrm{~d}, J=8.3 \mathrm{~Hz}, 2 \mathrm{H}), 7.56(\mathrm{~d}, J=8.3 \mathrm{~Hz}, 2 \mathrm{H})$, $7.15(\mathrm{~d}, J=15.6 \mathrm{~Hz}, 2 \mathrm{H}), 6.73(\mathrm{~d}, J=15.6 \mathrm{~Hz}, 2 \mathrm{H}), 6.69(\mathrm{~s}, 1 \mathrm{H}), 1.36(\mathrm{~s}, 9 \mathrm{H}) \mathrm{ppm} .{ }^{13} \mathrm{C}-\mathrm{NMR}(101$ $\left.\mathrm{MHz}, \mathrm{MeOD}-d_{4}\right): \delta=194.30,173.04,168.81,158.65,139.57,135.01,128.98,128.74,126.89$, 36.03, 31.44, 20.73 ppm.

Ethyl 3-azidopropanoate (76): Ethyl 3-bromopropanoate (75, $0.50 \mathrm{mg}, 2.8 \mathrm{mmol}, 1.0 \mathrm{eq})$ was dissolved in $20 \mathrm{~mL}$ DMF and sodium azide $(0.27 \mathrm{~g}, 4.2 \mathrm{mmol}, 1.5 \mathrm{eq})$ was added. The mixture was heated to $80{ }^{\circ} \mathrm{C}$ for 18 hours. After cooling to room temperature saturated aqueous $\mathrm{NaCl}$ solution $(20 \mathrm{~mL})$ was added, and the mixture was extracted with ethyl acetate $(3 \times 50 \mathrm{~mL})$. The organic layers were combined, dried over $\mathrm{Na}_{2} \mathrm{SO}_{4}$ and the solvents were evaporated in vacuo to afford the product as a brown-yellow oil (197 mg, 50\%). The product was reacted without further purification and characterization.

Ethyl 3-[4-(4-tert-butylphenyl)-1H-1,2,3-triazol-1-yl]propanoate (78): Ethyl 3-azidopropanoate (76, $183 \mathrm{mg}, 1.28 \mathrm{mmol}, 1.00 \mathrm{eq})$ and 4-tert-butylphenylacetylene (77, $203 \mathrm{mg}, 1.28 \mathrm{mmol}$, $1.00 \mathrm{eq}$ ) were suspended in a mixture of $6 \mathrm{~mL}$ water and $6 \mathrm{~mL}$ tert-butanol. A freshly prepared aqueous solution of sodium ascorbate $(1 \mathrm{M}, 26 \mathrm{mg}, 0.13 \mathrm{mmol}, 0.10 \mathrm{eq})$ and $\mathrm{CuSO}_{4}(2 \mathrm{mg}$, $0,01 \mathrm{mmol}, 0.01 \mathrm{eq}$ ) was added, and the resulting mixture was stirred at ambient temperature for 18 hours. Water $(50 \mathrm{~mL})$ was added and the mixture was extracted with ethyl acetate $(3 \times 50 \mathrm{~mL})$. The organic layers were combined, dried over $\mathrm{Na}_{2} \mathrm{SO}_{4}$ and the solvents were evaporated in vacuo. The crude product was purified by column chromatography in a gradient of hexane/EtOAc (4:1 to $1: 1)$ to afford the title compound as a yellow oil (159 mg, $41 \%)$. $R_{f}$ (hexane/EtOAc = 1:1) $=0.61$. ${ }^{1} \mathrm{H}-\mathrm{NMR}\left(500 \mathrm{MHz}, \mathrm{MeOD}-d_{4}\right): \delta=8.26(\mathrm{~s}, 1 \mathrm{H}), 7.73-7.71(\mathrm{~m}, 2 \mathrm{H}), 7.48-7.46(\mathrm{~m}, 2 \mathrm{H}), 4.71(\mathrm{t}, J=$ $6.6 \mathrm{~Hz}, 2 \mathrm{H}), 4.14(\mathrm{q}, J=7.1 \mathrm{~Hz}, 2 \mathrm{H}), 3.04(\mathrm{t}, J=6.6 \mathrm{~Hz}, 2 \mathrm{H}), 1.34(\mathrm{~s}, 9 \mathrm{H}), 1.22(\mathrm{t}, J=7.1 \mathrm{~Hz}, 3 \mathrm{H})$ 
ppm. ${ }^{13} \mathrm{C}-\mathrm{NMR}\left(126 \mathrm{MHz}, \mathrm{MeOD}-d_{4}\right): \delta=172.13,152.63,148.74,128.80,126.87,126.44,122.43$, 62.06, 47.07, 35.50, 35.36, 31.68, $14.41 \mathrm{ppm}$.

X-ray powder diffraction. The absolute configuration of compounds 10, 13 and 17 was determined in solid state based on X-ray powder diffraction data. X-ray powder diffraction measurements were performed in Debye-Scherrer geometry on a STOE STADI-P diffractometer (STOE \& Cie GmbH., Darmstadt, Germany) equipped with a curved $\mathrm{Ge}(111)$ monochromator and a position sensitive detector (Mythen $1 \mathrm{~K}$, Dectris). Cu-Ka $\alpha_{1}$ radiation $(\lambda=1.5406 \AA$ ) was used. Approx. $10 \mathrm{mg}$ of the respective sample was placed in a glass capillary $(\varnothing=0.7 \mathrm{~mm})$ and sealed. The capillaries were mounted on the diffractometer and rotated/spun during the measurements. All measurements were operated at room temperature. Each measurement range covered a 2Theta range of $2-90^{\circ}$ in $0.015^{\circ}$ steps, moving the detector in $0.5^{\circ}$ steps with an exposure time of $90 \mathrm{~s} / \mathrm{step}$ (total measurement time per sample: about 5 hours for 3 ranges). The data were collected with the STOE WinX ${ }^{\text {POW }}$ software (STOE \& Cie GmbH., Darmstadt, Germany). Resulting powder diagrams were indexed with $\mathrm{DICVOL}^{2}$ to find correct unit cells. After defining the space group (SYSTEVAL, STOE), a molecular model was developed and the structure solution process was run using simulated annealing in $\mathrm{DASH}^{3}$. The best reliable solutions were selected for structural refinement with TOPAS v6 ${ }^{4}$. Figure S1 was prepared using Mercury $2020.3^{5}$. 


\section{Methods for in vitro characterization}

Hybrid reporter gene assays. The plasmids pFA-CMV-NR-LBD for hPPARa ${ }^{6}, h P P A R \gamma^{6}$,

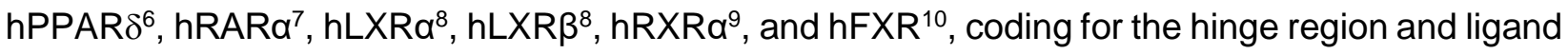
binding domain of the canonical isoform of the respective nuclear receptor, $p F R$-Luc (Stratagene, La Jolla, CA, USA; reporter) and pRL-SV40 (Promega, Madison, WI, USA; internal control) were used for the hybrid reporter gene assays. HEK293T cells (German Collection of Microorganisms and Cell Culture GmbH, DSMZ) were cultured in Dulbecco's modified Eagle's medium (DMEM), high glucose supplemented with $10 \%$ fetal calf serum (FCS), sodium pyruvate $(1 \mathrm{mM})$, penicillin $(100 \mathrm{U} / \mathrm{mL})$, and streptomycin $(100 \mu \mathrm{g} / \mathrm{mL})$ at $37{ }^{\circ} \mathrm{C}$ and $5 \% \mathrm{CO}_{2}$ and seeded in 96-well plates $\left(3 \times 10^{4}\right.$ cells/well) twenty-four hours prior to transfection. Before transfection, medium was changed to Opti-MEM without supplements and transient transfection with above mentioned plasmids ( $p F R$-Luc, pRL-SV40 and one pFA-CMV-NR-LBD clone) was carried out with Lipofectamine LTX reagent (Invitrogen) according to the manufacturer's protocol. Five hours after transfection, medium was changed to Opti-MEM supplemented with penicillin $(100 \mathrm{U} / \mathrm{mL})$ and streptomycin $(100 \mu \mathrm{g} / \mathrm{mL})$ additionally containing $0.1 \%$ dimethyl sulfoxide (DMSO) and the respective test compound or $0.1 \%$ DMSO alone as untreated control. Each concentration was tested in duplicates and each experiment was repeated independently at least two times. Following overnight (14-16 h) incubation, cells were assayed for luciferase activity using the DualGlo Luciferase Assay System (Promega) according to the manufacturer's protocol. Luminescence was measured with a Tecan Spark luminometer (Tecan Deutschland GmbH, Germany). Normalization of transfection efficiency and cell growth was done by division of firefly luciferase data by renilla luciferase data and multiplying the value by 1000 resulting in relative light units $(R L U)$. Fold activation was obtained by dividing the mean RLU of a test compound by the mean RLU of the untreated control. Max. relative activation refers to fold reporter activity divided by the fold activation of respective reference agonist (PPARa: $1 \mu \mathrm{M}$ GW7647; PPARY: $1 \mu \mathrm{M}$ pioglitazone;

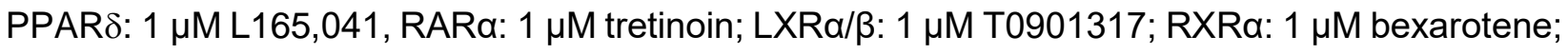
FXR: $1 \mu \mathrm{M}$ GW4064) treated cells. All hybrid assays were validated with the respective reference agonists which yielded $\mathrm{EC}_{50}$ values in agreement with the literature.

FXR:RXR activation in hepatocytes. HepG2 cells (DSMZ) were cultured in DMEM, high glucose supplemented with $10 \%$ fetal calf serum (FCS), sodium pyruvate $(1 \mathrm{mM})$, penicillin $(100 \mathrm{U} / \mathrm{mL})$, and streptomycin $(100 \mu \mathrm{g} / \mathrm{mL})$ at $37{ }^{\circ} \mathrm{C}$ and $5 \% \mathrm{CO}_{2}$ and seeded twenty-four hours prior to transfection in 96 -well plates $\left(3 \times 10^{4}\right.$ cells/well) pre-coated with Collagen G solution. Before transfection, medium was changed to Opti-MEM without supplements and transient transfection was carried out using Lipofectamine 3000 reagent (Invitrogen) according to the manufacturer's protocol with pGL3basic-BSEP10,11, coding for a firefly luciferase reporter gene under control of the human full length FXR response element from the promoter region of BSEP, and pRL-SV40 (Promega, for normalization). Five hours after transfection, medium was changed to Opti-MEM 
supplemented with penicillin $(100 \mathrm{U} / \mathrm{mL})$ and streptomycin $(100 \mu \mathrm{g} / \mathrm{mL})$, additionally containing $0.1 \%$ DMSO and the respective test compound or $0.1 \%$ DMSO alone as untreated control. Each concentration was tested in duplicates and each experiment was repeated independently at least three times. After overnight (14-16 h) incubation the cells were assayed for luciferase activity as described above. The assay was validated with reference FXR agonists 1 and 2 which yielded $\mathrm{EC}_{50}$ values in agreement with the literature.

Quantification of FXR regulated gene expression in HepG2 cells. FXR target gene quantification was performed as described previously ${ }^{12}$. HepG2 cells were grown in DMEM high glucose, supplemented with 10\% FCS, $1 \mathrm{mM} \mathrm{SP}$, penicillin $(100 \mathrm{U} / \mathrm{mL})$, and streptomycin (100 $\mu \mathrm{g} / \mathrm{mL}$ ) at $37{ }^{\circ} \mathrm{C}$ and $5 \% \mathrm{CO}_{2}$. Cells were seeded in 6 -well plates $\left(2 \times 10^{6}\right.$ per well). $24 \mathrm{~h}$ after seeding, medium was changed to MEM supplemented with $1 \%$ charcoal stripped FCS, penicillin (100 U/mL), streptomycin $(100 \mu \mathrm{g} / \mathrm{mL})$, and $2 \mathrm{mM} \mathrm{L}$-glutamine. After an additional $24 \mathrm{~h}$, cells were incubated with test compound $18(10 \mu \mathrm{M})$ or CDCA $(30 \mu \mathrm{M})$ dissolved in the same medium with $0.1 \%$ DMSO or medium with $0.1 \%$ DMSO alone as untreated control for $8 \mathrm{~h}$, harvested, washed with cold phosphate buffered saline (PBS), and then directly used for RNA extraction. Total RNA was extracted using the total RNA Mini Kit (R6834-02, Omega Bio-Tek, Inc., Norcross, GA, USA). An amount of $2 \mu \mathrm{g}$ of RNA was then reverse-transcribed into cDNA using the high capacity cDNA reverse transcription kit (4368814, Thermo Fischer Scientific, Inc.) according to the manufacturer's protocol. FXR regulated gene expression was studied by quantitative real time PCR analysis with a StepOnePlus System (Life Technologies, Carlsbad, CA, USA) using PowerSYBRGreen (Life Technologies; $12.5 \mu \mathrm{L}$ per well). Each sample was set up in duplicates and repeated in three independent experiments. Data were analyzed by the comparative $\Delta \Delta \mathrm{Ct}$ method with glycerinaldehyde 3-phosphate dehydrogenase (GAPDH) as reference gene. The following primers were used: hGAPDH, 5-ATA TGA TTC CAC CCA TGG CA (fw), 5-GAT GAT GAC CCT TTT GGC TC (rev); hSHP, 5-GCT GTC TGG AGT CCT TCT GG (fw), 5-CCA ATG ATA GGG CGA AAG AAG AG (rev); hBSEP, 5-CAT GGT GCA AGA AGT GCT GAG T (fw), 5-AAG CGA TGA GCA ACT GAA ATG AT (rev).

Isothermal titration calorimetry (ITC). ITC was conducted on a TA Instruments Affinity ITC (TA Instruments, New Castle, Delaware, USA) using recombinant FXR LBD protein ${ }^{13}$ dissolved in buffer pH 8.3 containing $10 \mathrm{mM}$ Tris, $100 \mathrm{mM} \mathrm{NaCl}, 5 \mathrm{mM}$ DTT and 1\% DMSO. The FXR ligands 17, 18 or $24(100-150 \mu \mathrm{M})$ were dissolved in the same buffer, placed into the ITC syringe and titrated to $172 \mu \mathrm{L}$ of FXR LBD protein $(25-40 \mu \mathrm{M})$. The titration was performed at a temperature of $25{ }^{\circ} \mathrm{C}$ with a stirring rate of $75 \mathrm{rpm}$ and $2.5 \mu \mathrm{L}$ injection volume (40 injections). The first injection had a reduced volume of $1.0 \mu \mathrm{L}$. An interval of $300 \mathrm{~s}$ was maintained between injections. ITC raw data were analyzed using NanoAnalyze software package (version 3.7.5). An independent binding model was used to fit the reaction enthalpy $(\Delta \mathrm{H})$, binding affinity constant $\left(\mathrm{K}_{\mathrm{d}}\right)$, and stoichiometry (n). 
Microsomal stability assay. The solubilized test compound ( $5 \mu \mathrm{L}$, final concentration $10 \mu \mathrm{M})$ was preincubated at $37^{\circ} \mathrm{C}$ in $432 \mu \mathrm{L}$ of phosphate buffer $(0.1 \mathrm{M}, \mathrm{pH}$ 7.4) together with $50 \mu \mathrm{L}$ NADPH regenerating system (30 mM glucose-6-phosphate, $4 \mathrm{U} / \mathrm{mL}$ glucose-6-phosphate dehydrogenase, $10 \mathrm{mM}$ NADP, $30 \mathrm{mM} \mathrm{MgCl}$ ). After $5 \mathrm{~min}$, the reaction was started by the addition of $13 \mu \mathrm{L}$ of microsome mix from the liver of Sprague-Dawley rats (Invitrogen; $20 \mathrm{mg}$ protein/mL in $0.1 \mathrm{M}$ phosphate buffer) in a shaking water bath at $37^{\circ} \mathrm{C}$. The reaction was stopped by adding $500 \mu \mathrm{L}$ of ice-cold methanol at $0,15,30$ and $60 \mathrm{~min}$. The samples were centrifuged at $5000 \mathrm{~g}$ for $5 \mathrm{~min}$ at $4^{\circ} \mathrm{C}$. The supernatants were analyzed and the test compound was quantified by HPLC: The composition of the mobile phase is adapted to the test compound in a range of $\mathrm{MeOH} 40-90 \%$ and water $(0.1 \%$ formic acid) $10-60 \%$; flow-rate: $1 \mathrm{~mL} / \mathrm{min}$; stationary phase: MultoHigh Phenyl phase, $5 \mu \mathrm{m}, 250 \times 4$, precolumn, phenyl, $5 \mu \mathrm{m}, 20 \times 4$; detection wavelength: 330 and $254 \mathrm{~nm}$; injection volume: $50 \mu \mathrm{L}$. Control samples were performed to check the test compound's stability in the reaction mixture: first control was without NADPH, which is needed for the enzymatic activity of the microsomes, second control was with inactivated microsomes (incubated for 20 min at $90^{\circ} \mathrm{C}$ ), and third control was without test compound (to determine the baseline). The amounts of the test compound were quantified by an external calibration curve. Data are expressed as the mean \pm SEM remaining compound from three independent experiments.

WST-1 toxicity assay. The WST-1 assay from Roche (Roche Diagnostics, Rotkreuz, Switzerland) was performed according to the manufacturer's protocol. In brief, HepG2 cells were seeded in DMEM supplemented with $1 \mathrm{mM}$ sodium pyruvate, penicillin (100 U/mL), streptomycin (100 $\mu \mathrm{g} / \mathrm{mL}$ ), and $10 \% \mathrm{FCS}$ in 96 -well plates $\left(3 \times 10^{4}\right.$ cells/well). After $24 \mathrm{~h}$, medium was changed to DMEM supplemented with penicillin $(100 \mathrm{U} / \mathrm{mL})$, streptomycin $(100 \mu \mathrm{g} / \mathrm{mL})$, and $1 \% \mathrm{FCS}$, additionally containing the test compounds and $0.1 \%$ DMSO or $0.1 \%$ DMSO alone as negative control. After $48 \mathrm{~h}$, WST reagent (Roche) was added to each well according to the manufacturer's instructions. After $45 \mathrm{~min}$ incubation, absorbance $(450 \mathrm{~nm} /$ reference: $620 \mathrm{~nm})$ was determined with a Tecan Spark M luminometer (Tecan). Each experiment was repeated four times in duplicates.

BSEP-based full-length FXR:RXR reporter gene assay. Plasmids. pGL3basic-BSEP ${ }^{10,11}$ (Promega Corporation, Fitchburg, WI, USA) contains a shortened construct of the promotor of the bile salt export protein (BSEP) cloned into the Sacl/Nhel cleavage site in front of the luciferase gene and was used as a reporter plasmid. pcDNA3-hFXR ${ }^{11}$ and pSG5-hRXR ${ }^{14}$ served for receptor overexpression. pRL-SV40 (Promega) was co-transfected as a control for normalization of transfection efficiency and cell growth. Assay procedure. HeLa cells were grown in DMEM high glucose supplemented with $10 \% \mathrm{FCS}$, sodium pyruvate $(1 \mathrm{mM})$, penicillin $(100 \mathrm{U} / \mathrm{mL})$ and streptomycin $(100 \mu \mathrm{g} / \mathrm{mL})$ at $37^{\circ} \mathrm{C}$ and $5 \% \mathrm{CO}_{2}$, and seeded in 96-well plates $24 \mathrm{~h}$ before transfection with a density of 8000 cells per well. $1 \mathrm{~h}$ before transfection, medium was changed to DMEM high glucose, supplemented with sodium pyruvate $(1 \mathrm{mM})$, penicillin $(100 \mathrm{U} / \mathrm{mL})$, streptomycin $(100 \mu \mathrm{g} / \mathrm{mL})$ and $0.5 \%$ charcoal-stripped FCS. Cells were then transiently 
transfected with above described plasmids using the calcium phosphate transfection method. 16 $\mathrm{h}$ after transfection, medium was changed to DMEM high glucose, supplemented with sodium pyruvate $(1 \mathrm{mM})$, penicillin $(100 \mathrm{U} / \mathrm{mL})$, streptomycin $(100 \mu \mathrm{g} / \mathrm{mL})$ and $0.5 \%$ charcoal-stripped FCS. $24 \mathrm{~h}$ after transfection, medium was changed to DMEM without phenol red, supplemented with sodium pyruvate $(1 \mathrm{mM})$, penicillin $(100 \mathrm{U} / \mathrm{mL})$, streptomycin $(100 \mu \mathrm{g} / \mathrm{mL})$, L-glutamine (2 $\mathrm{mM}$ ) and $0.5 \%$ charcoal-stripped FCS, now additionally containing $0.1 \%$ DMSO and the respective test compound or $0.1 \%$ DMSO alone as untreated control. Each sample was tested in triplicate wells and each experiment was repeated independently at least three times. Following $24 \mathrm{~h}$ incubation with the test compounds, cells were assayed for luciferase activity using Dual-Glo Luciferase Assay System (Promega) according to the manufacturer's protocol. Luminescence was measured with a Tecan Spark luminometer (Tecan). Normalization of transfection efficiency and cell growth was done by division of firefly luciferase data by renilla luciferase data multiplied by 1000 resulting in relative light units $(R L U)$. Fold activation was obtained by dividing the mean $R L U$ of the tested compound at a respective concentration by the mean RLU of untreated control. 


\section{Computational procedures}

General. Calculations were conducted in Molecular Operating Environment (MOE, version 2018.0101, Chemical Computing Group Inc. Montreal, QC, Canada) using default settings for each tool/function unless stated otherwise. Amber10:EHT was used as default force field for all calculations.

Docking was performed using two different $X$-ray structures of the FXR ligand binding domain in complex with CDCA (PDB code 4QE6, purple) or GW4064 (PDB code 3DCT, red). Protonation state of the complexes was adjusted using the MOE QuickPrep tool. Redocking of the crystallized ligands resulted in a binding pose with RMSD 0.1497 relative to the crystallized binding mode for CDCA and RMSD 0.1140 for GW4064, respectively. Compounds 14 and 18 were prepared using MOE Wash tool: Protonation state dominant at $\mathrm{pH}$ 7; Coordinates Rebuild 3D; Preserved Existing Chirality. Docking was performed using the following settings from the MOE Dock tool: Receptor: Receptor + Solvent; Site: Ligand Atoms; Placement: Triangle Matcher; Score: London dG; Poses: 100; Refinement: Rigid receptor; Refinement Score: GBVIMSA dG; Poses: 10. The highest ranked binding-mode was used. Overlay of all ten docking poses is depicted separately for 18. 


\section{Supporting References}

(1) Spektroskopische Methoden in Der Organischen Chemie; Hesse, M., Meier, H., Zeeh, B., Eds.; Georg Thieme Verlag: Stuttgart, 2012. https://doi.org/10.1055/b-002-46984.

(2) Boultif, A.; Loueer, D. Indexing of Powder Diffraction Patterns for Low-Symmetry Lattices by the Successive Dichotomy Method. J. Appl. Crystallogr. 1991, 24 (pt 6), 987-993. https://doi.org/10.1107/S0021889891006441.

(3) David, W. I. F.; Shankland, K.; Van De Streek, J.; Pidcock, E.; Motherwell, W. D. S.; Cole, J. C. DASH: A Program for Crystal Structure Determination from Powder Diffraction Data. J. Appl. Crystallogr. 2006, 39 (6), 910-915. https://doi.org/10.1107/S0021889806042117.

(4) Coelho, A. A. TOPAS and TOPAS-Academic: An Optimization Program Integrating Computer Algebra and Crystallographic Objects Written in C++: An. J. Appl. Crystallogr. 2018, 51 (1), 210-218. https://doi.org/10.1107/S1600576718000183.

(5) Macrae, C. F.; Edgington, P. R.; McCabe, P.; Pidcock, E.; Shields, G. P.; Taylor, R.; Towler, M.; Van De Streek, J. Mercury: Visualization and Analysis of Crystal Structures. Journal of Applied Crystallography. International Union of Crystallography June 10, 2006, pp 453-457. https://doi.org/10.1107/S002188980600731X.

(6) Rau, O.; Wurglics, M.; Paulke, A.; Zitzkowski, J.; Meindl, N.; Bock, A.; Dingermann, T.; Abdel-Tawab, M.; Schubert-Zsilavecz, M. Carnosic Acid and Carnosol, Phenolic Diterpene Compounds of the Labiate Herbs Rosemary and Sage, Are Activators of the Human Peroxisome Proliferator-Activated Receptor Gamma. Planta Med. 2006, 72 (10), 881-887. https://doi.org/10.1055/s-2006-946680.

(7) Pollinger, J.; Gellrich, L.; Schierle, S.; Kilu, W.; Schmidt, J.; Kalinowsky, L.; Ohrndorf, J.; Kaiser, A.; Heering, J.; Proschak, E.; Merk, D. Tuning Nuclear Receptor Selectivity of Wy14,643 towards Selective Retinoid X Receptor Modulation. J. Med. Chem. 2019, 62 (4), 2112-2126. https://doi.org/10.1021/acs.jmedchem.8b01848.

(8) Heitel, P.; Achenbach, J.; Moser, D.; Proschak, E.; Merk, D. DrugBank Screening Revealed Alitretinoin and Bexarotene as Liver X Receptor Modulators. Bioorg. Med. Chem. Lett. 2017, 27 (5), 1193-1198. https://doi.org/10.1016/j.bmcl.2017.01.066.

(9) Heitel, P.; Gellrich, L.; Kalinowsky, L.; Heering, J.; Kaiser, A.; Ohrndorf, J.; Proschak, E.; Merk, D. ComputerAssisted Discovery and Structural Optimization of a Novel Retinoid X Receptor Agonist Chemotype. ACS Med. Chem. Lett. 2019, 10 (2), 203-208. https://doi.org/10.1021/acsmedchemlett.8b00551.

(10) Schmidt, J.; Klingler, F.-M.; Proschak, E.; Steinhilber, D.; Schubert-Zsilavecz, M.; Merk, D. NSAIDs Ibuprofen, Indometacin, and Diclofenac Do Not Interact with Farnesoid X Receptor. Sci. Rep. 2015, 5, 14782. https://doi.org/10.1038/srep14782.

(11) Steri, R.; Achenbach, J.; Steinhilber, D.; Schubert-Zsilavecz, M.; Proschak, E. Investigation of Imatinib and Other Approved Drugs as Starting Points for Antidiabetic Drug Discovery with FXR Modulating Activity. Biochem. Pharmacol. 2012, 83 (12), 1674-1681. https://doi.org/10.1016/j.bcp.2012.02.027.

Merk, D.; Lamers, C.; Ahmad, K.; Carrasco Gomez, R.; Schneider, G.; Steinhilber, D.; Schubert-Zsilavecz, M. Extending the Structure-Activity Relationship of Anthranilic Acid Derivatives as Farnesoid x Receptor Modulators: Development of a Highly Potent Partial Farnesoid x Receptor Agonist. J. Med. Chem. 2014, 57 (19), 8035-8055. https://doi.org/10.1021/jm500937v.

(13) Merk, D.; Sreeramulu, S.; Kudlinzki, D.; Saxena, K.; Linhard, V.; Gande, S. L.; Hiller, F.; Lamers, C.; Nilsson, E.; Aagaard, A.; Wissler, L.; Dekker, N.; Bamberg, K.; Schubert-Zsilavecz, M.; Schwalbe, H. Molecular Tuning of Farnesoid X Receptor Partial Agonism. Nat. Commun. 2019, 10 (1), 2915. https://doi.org/10.1038/s41467019-10853-2.

(14) Seuter, S.; Väisänen, S.; Rådmark, O.; Carlberg, C.; Steinhilber, D. Functional Characterization of Vitamin D Responding Regions in the Human 5-Lipoxygenase Gene. Biochim. Biophys. Acta - Mol. Cell Biol. Lipids 2007, 1771 (7), 864-872. https://doi.org/10.1016/j.bbalip.2007.04.007. 